\title{
Advanced Manufacturing Research for Healthcare
}

Mohan Edirisinghe FREng, FEuroAcadSci

Department of Mechanical Engineering

Faculty of Engineering Sciences

University College London

London, UK

m.edirisinghe@ucl.ac.uk

Website: www.EdirisingheLab.com 


\section{MICROFLUIDICS}

Many EPSRC Grants (e.g. EP/E012434/1) and UCL doctoral studentships

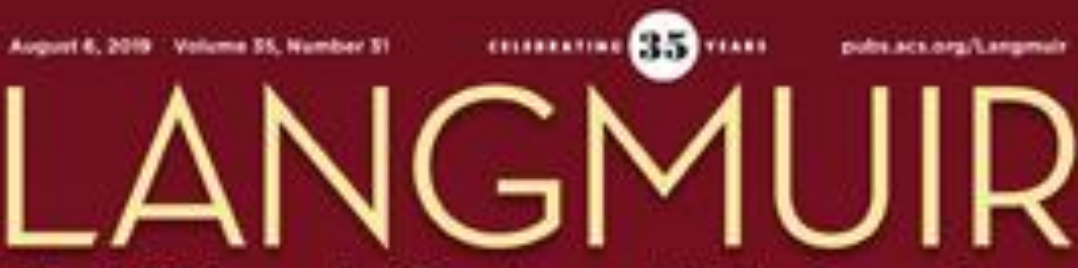

The ACS journal of fundamental interface science

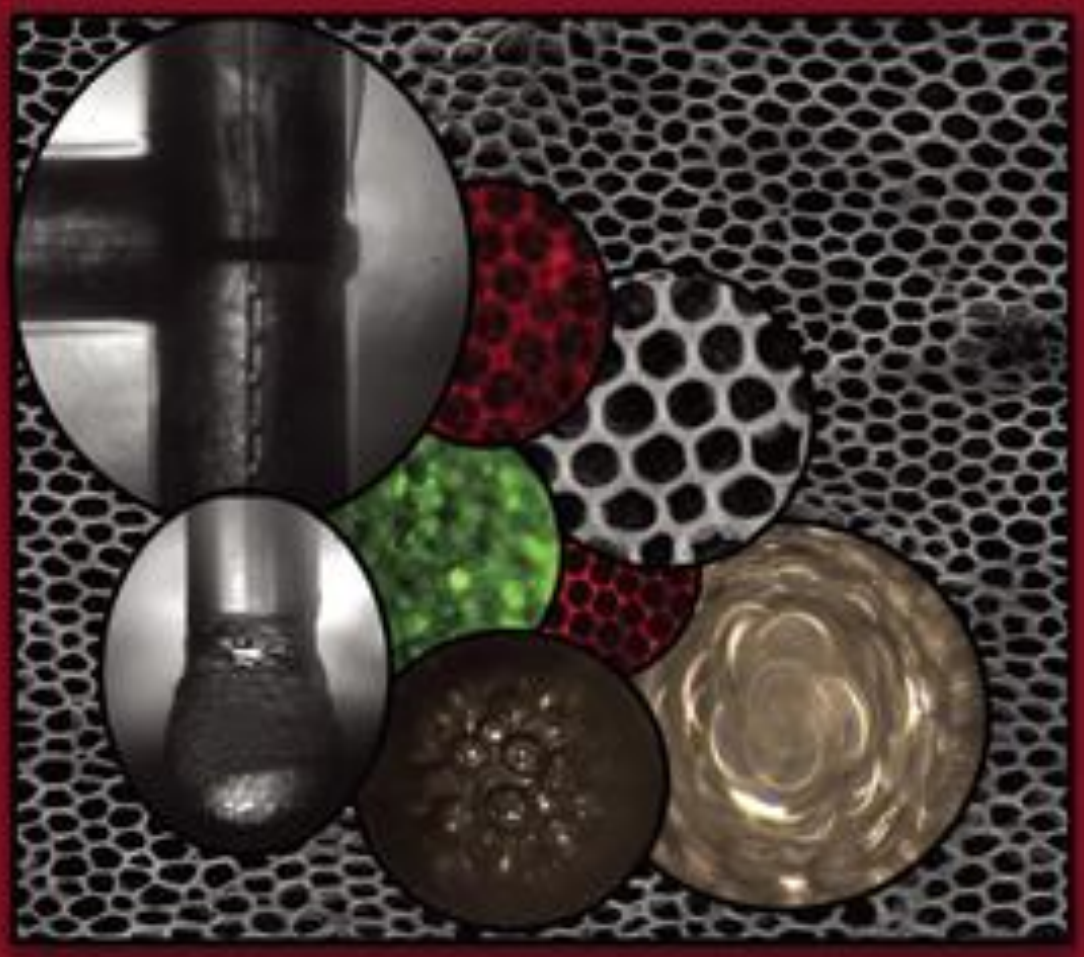

Microbubbles: A New Medical Frontier

\section{Invited Special Iss
06
th August 2019}

24 key papers by key leading researchers covering every part of the world 


\section{Microbubble size reduction}

(A): Triple (3) T-junction

Capillary size: $65 \mu \mathrm{m}$

Channel gap size: $65 \mu \mathrm{m}$

Gas Pressure: $80 \mathrm{kPa}$

BSA solution: 10 wt \%

Flow Rate: $650 \mu \mathrm{L} / \mathrm{min}$

(B): Triple (3) T-junction

Capillary size: $25 \mu \mathrm{m}$

Channel gap size: $25 \mu \mathrm{m}$

Gas Pressure: $80 \mathrm{kPa}$

BSA solution: 5 wt $\%$

Flow Rate: $400 \mu \mathrm{L} / \mathrm{min}$

The mean MB size is:

$\underline{12.8 \mu \mathrm{m}}$
The mean

$\mathrm{MB}$ size is:

$12.4 \mu \mathrm{m}$
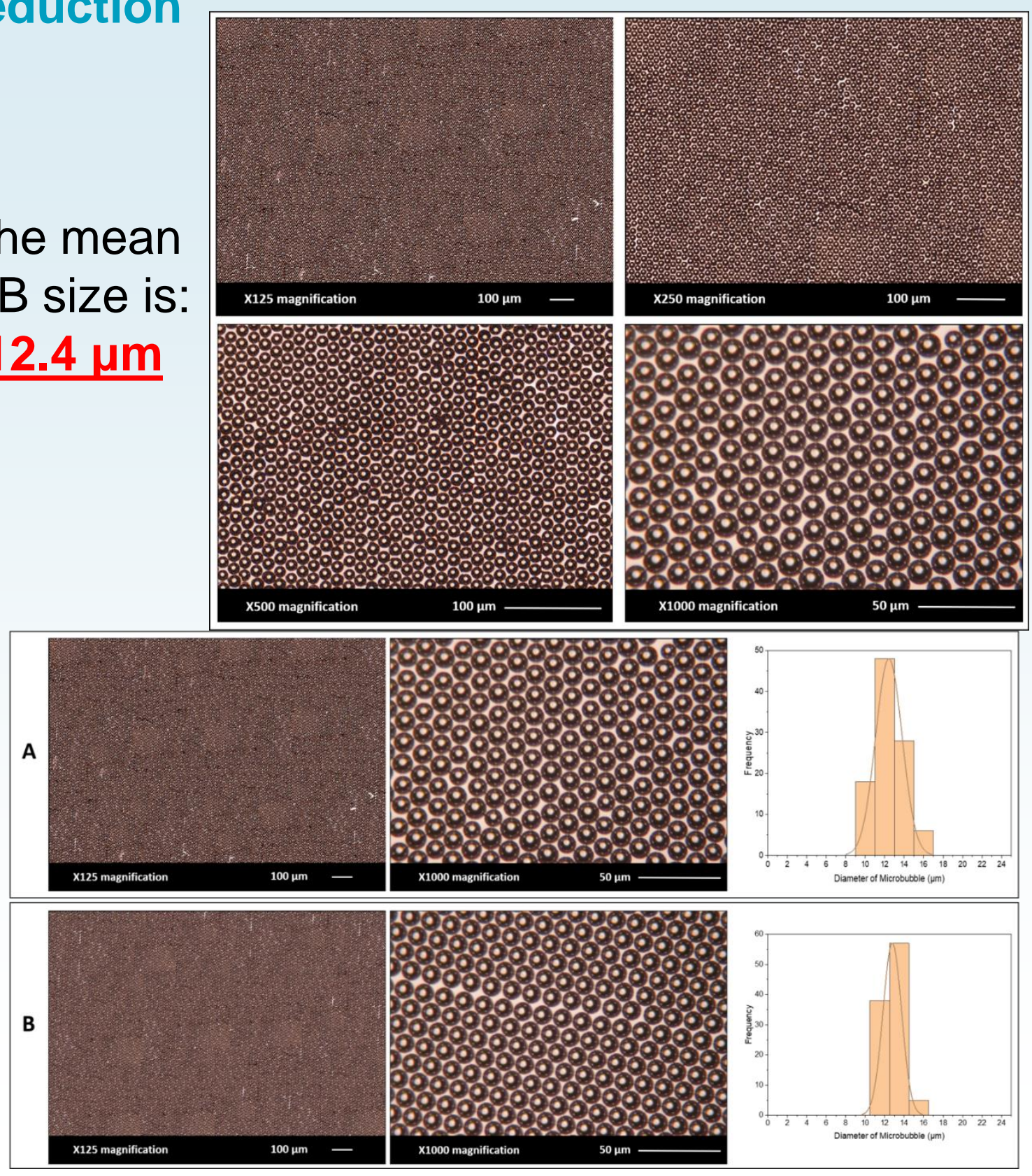
(C): Triple (3) T-junction

Capillary size: $25 \mu \mathrm{m}$ (gas inlet) and $65 \mu \mathrm{m}$ (rest) Channel gap size: $65 \mu \mathrm{m}$ Gas Pressure: $80 \mathrm{kPa}$ BSA solution: 10 wt \% Flow Rate: $700 \mu \mathrm{L} / \mathrm{min}$

(C): The mean MB size is: $\underline{9.9 \mu \mathrm{m}}$

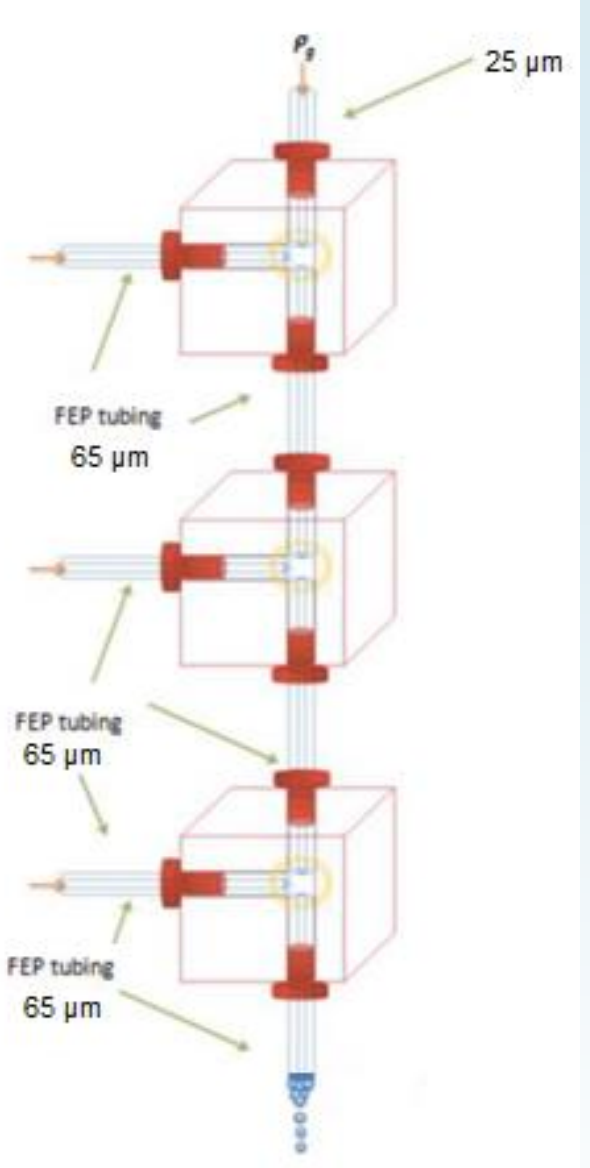

(A):
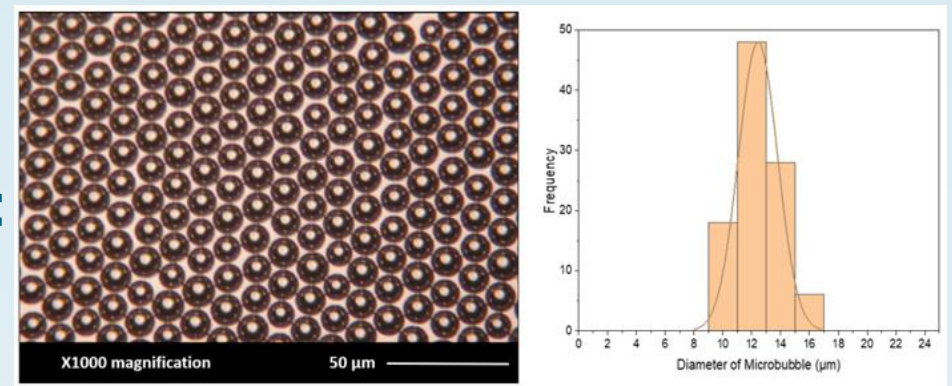

(B):
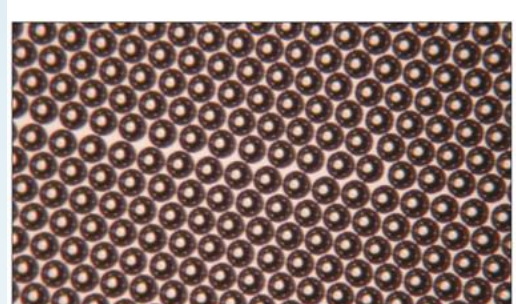
00000000000

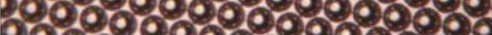

x1000 magnification

(C):
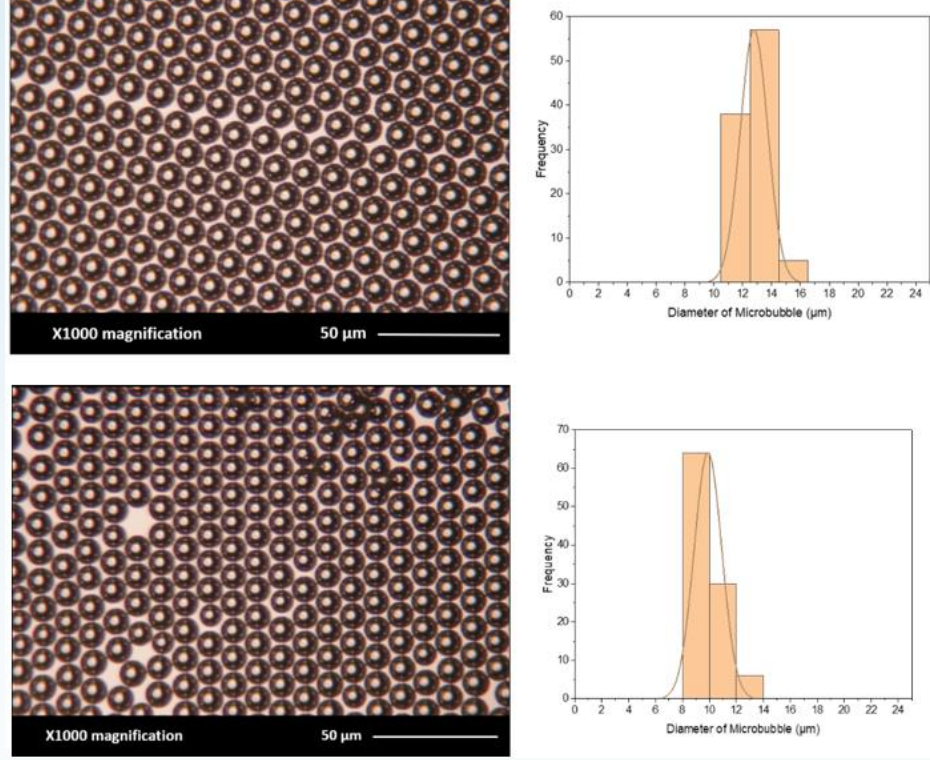

(D): Quadruple (4) T-junction Capillary size: $100 \mu \mathrm{m}$ Channel gap size: $100 \mu \mathrm{m}$ Gas Pressure: $80 \mathrm{kPa}$ BSA solution: 10 wt \% The mean MB size is: $8.7 \mu \mathrm{m}$
(D):

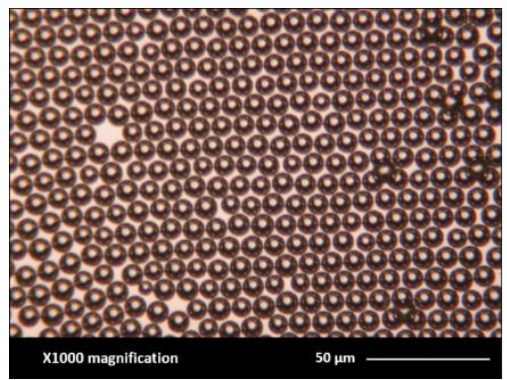

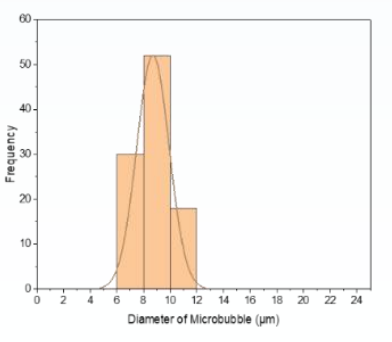




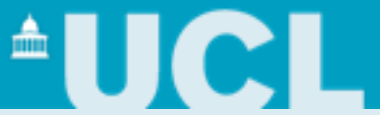

Microbubble size reduction with fission processes:

Quadruple (4) T-junction Capillary size: $65 \mu \mathrm{m}$ Channel gap size: $100 \mu \mathrm{m}$ Gas Pressure: $80 \mathrm{kPa}$ BSA solution: 10 wt $\%$ Flow Rate: $600 \mu \mathrm{L} / \mathrm{min}$

The mean MB size is: $\underline{6.6 \mu \mathrm{m}}$

Quadruple (4) T-junction Capillary size: $25 \mu \mathrm{m}$ (gas inlet) and $100 \mu \mathrm{m}$ (rest) Channel gap size: $150 \mu \mathrm{m}$ Gas Pressure: $80 \mathrm{kPa}$ BSA solution: 15 wt \% Flow Rate: $700 \mu \mathrm{L} / \mathrm{min}$ The mean MB size is: $3.3 \mu \mathrm{m}$
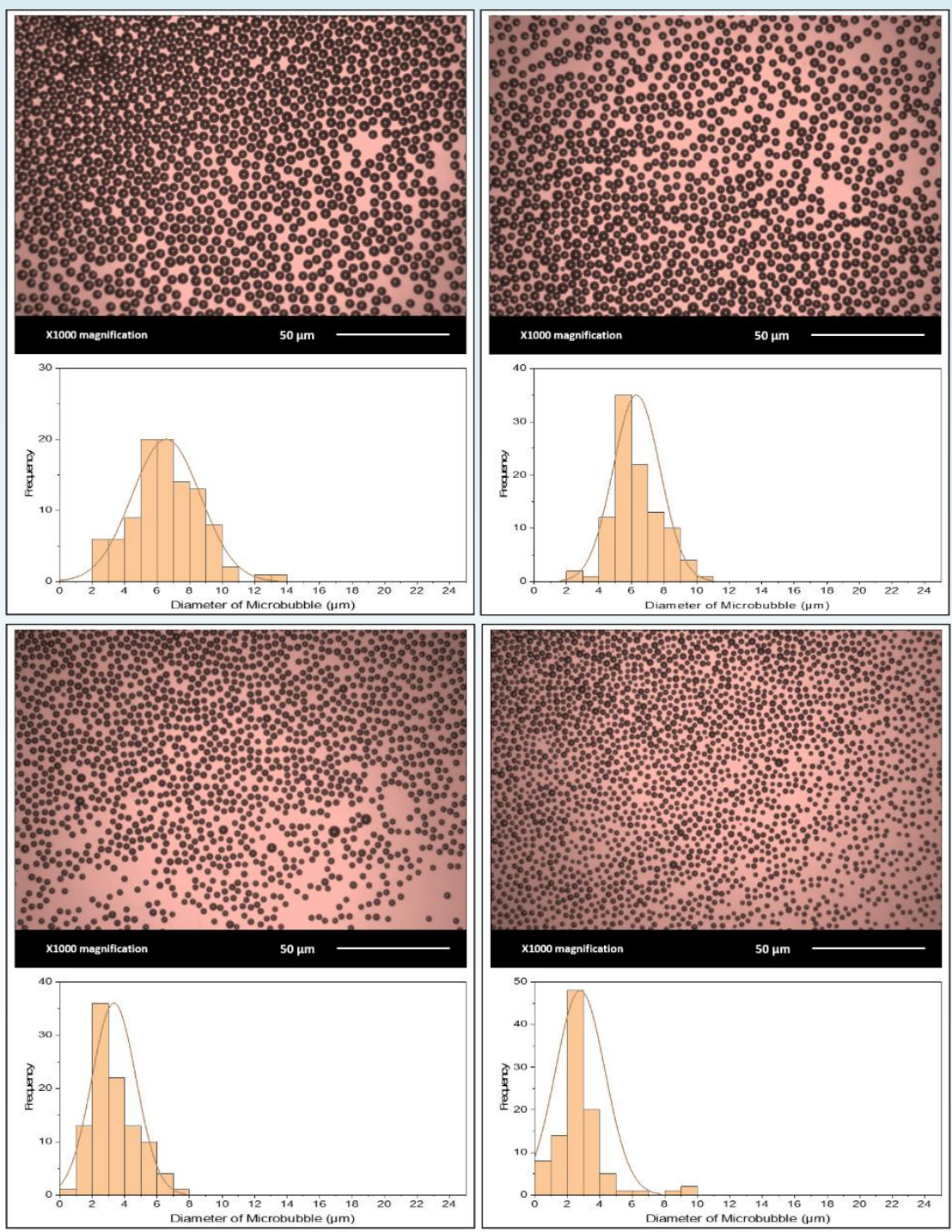

Quadruple (4) T-junction Capillary size: $25 \mu \mathrm{m}$ Channel gap size: $50 \mu \mathrm{m}$ Gas Pressure: $80 \mathrm{kPa}$ BSA solution: 15 wt $\%$ Flow Rate: $700 \mu \mathrm{L} / \mathrm{min}$ The mean MB size is: $\underline{6.30 \mu \mathrm{m}}$

Quadruple (4) T-junction Capillary size: $25 \mu \mathrm{m}$ (gas inlet) and $65 \mu \mathrm{m}$ (rest) Channel gap size: $100 \mu \mathrm{m}$ Gas Pressure: $80 \mathrm{kPa}$ BSA solution: 10 wt \% Flow Rate: $650 \mu \mathrm{L} / \mathrm{min}$ The mean MB size is: $2.80 \mu \mathrm{m}$ 
Comparison study:

\begin{tabular}{|c|c|c|c|c|c|}
\hline Capillary size: & $100 \mu \mathrm{m}$ & $65 \mu \mathrm{m}$ & $25 \mu \mathrm{m}$ & \multicolumn{2}{|c|}{$\begin{array}{c}25 \mu \mathrm{m} \text { for gas inlet } \\
65 \mu \mathrm{m} \text { for rest capillaries }\end{array}$} \\
\hline $\begin{array}{c}\text { Channel gap } \\
\text { distance: }\end{array}$ & $100 \mu \mathrm{m}$ & $65 \mu \mathrm{m}$ & $25 \mu \mathrm{m}$ & \multicolumn{2}{|c|}{$65 \mu \mathrm{m}$} \\
\hline Fission Process & Not occurred & Not occurred & Not occurred & \multicolumn{2}{|c|}{ Not occurred } \\
\hline $\begin{array}{c}\text { The smallest } \\
\text { MB size: }\end{array}$ & $22.8 \pm 1.4 \mu \mathrm{m}$ & $12.4 \pm 1.2 \mu \mathrm{m}$ & $12.8 \pm 1.7 \mu \mathrm{m}$ & \multicolumn{2}{|c|}{$9.9 \pm 1.3 \mu \mathrm{m}$} \\
\hline $\begin{array}{l}\text { The optimal } \\
\text { conditions: }\end{array}$ & 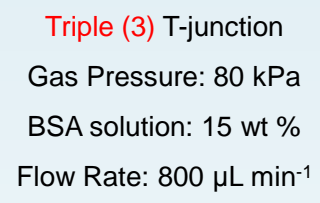 & $\begin{array}{l}\text { Triple (3) T-junction } \\
\text { Gas Pressure: } 80 \mathrm{kPa} \\
\text { BSA solution: } 10 \mathrm{wt} \% \\
\text { Flow Rate: } 650 \mu \mathrm{L} \mathrm{min}{ }^{-1}\end{array}$ & $\begin{array}{l}\text { Triple (3) T-junction } \\
\text { Gas Pressure: } 80 \mathrm{kPa} \\
\text { BSA solution: } 5 \mathrm{wt} \% \\
\text { Flow Rate: } 400 \mu \mathrm{L} \mathrm{min}{ }^{-1}\end{array}$ & \multicolumn{2}{|c|}{ 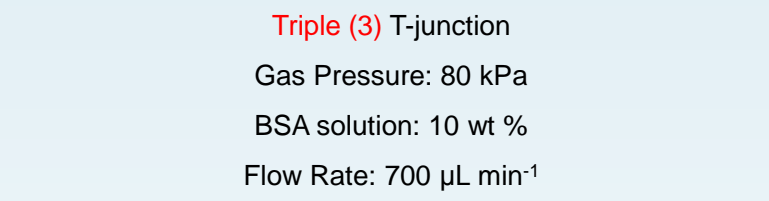 } \\
\hline $\begin{array}{c}\text { lifetime of MBs } \\
\text { (without adding } \\
\text { SiQD): }\end{array}$ & $40.0 \pm 2.0 \mathrm{mins}$ & $25.0 \pm 1.5 \mathrm{mins}$ & $5.0 \pm 0.5 \mathrm{mins}$ & \multicolumn{2}{|c|}{$25.0 \pm 2.5 \mathrm{mins}$} \\
\hline Capillary size: & $100 \mu \mathrm{m}$ & $65 \mu \mathrm{m}$ & $25 \mu \mathrm{m}$ & $\begin{array}{c}25 \mu \mathrm{m} \text { for gas inlet } \\
100 \mu \mathrm{m} \text { for rest capillaries }\end{array}$ & $\begin{array}{c}25 \mu \mathrm{m} \text { for gas inlet } \\
65 \mu \mathrm{m} \text { for rest capillaries }\end{array}$ \\
\hline $\begin{array}{c}\text { Channel gap } \\
\text { distance: }\end{array}$ & $100 \mu \mathrm{m}$ & $100 \mu \mathrm{m}$ & $50 \mu \mathrm{m}$ & $150 \mu \mathrm{m}$ & $100 \mu \mathrm{m}$ \\
\hline Fission Process & Not occurred & Occurred & Occurred & Occurred & Occurred \\
\hline $\begin{array}{c}\text { The smallest } \\
\text { MB size: }\end{array}$ & $8.7 \pm 0.8 \mu \mathrm{m}$ & $6.6 \pm 2.1 \mu \mathrm{m}$ & $6.3 \pm 1.4 \mu \mathrm{m}$ & $3.3 \pm 1.4 \mu \mathrm{m}$ & $2.8 \pm 1.5 \mu \mathrm{m}$ \\
\hline $\begin{array}{l}\text { The optimal } \\
\text { conditions: }\end{array}$ & $\begin{array}{l}\text { Quadruple (4) T-junction } \\
\text { Gas Pressure: } 80 \mathrm{kPa} \\
\text { BSA solution: } 15 \text { wt \% } \\
\text { Flow Rate: } 800 \mu \mathrm{L} \mathrm{min}{ }^{-1}\end{array}$ & $\begin{array}{l}\text { Quadruple (4) T-junction } \\
\text { Gas Pressure: } 80 \mathrm{kPa} \\
\text { BSA solution: } 10 \text { wt \% } \\
\text { Flow Rate: } 600 \mu \mathrm{L} \mathrm{min}{ }^{-1}\end{array}$ & $\begin{array}{l}\text { Quadruple (4) T-junction } \\
\text { Gas Pressure: } 80 \mathrm{kPa} \\
\text { BSA solution: } 5 \mathrm{wt} \% \\
\text { Flow Rate: } 300 \mu \mathrm{L} \mathrm{min}^{-1}\end{array}$ & $\begin{array}{l}\text { Quadruple (4) T-junction } \\
\text { Gas Pressure: } 80 \mathrm{kPa} \\
\text { BSA solution: } 15 \text { wt \% } \\
\text { Flow Rate: } 700 \mu \mathrm{L} \mathrm{min}{ }^{-1}\end{array}$ & $\begin{array}{l}\text { Quadruple (4) T-junction } \\
\text { Gas Pressure: } 80 \mathrm{kPa} \\
\text { BSA solution: } 10 \mathrm{wt} \% \\
\text { Flow Rate: } 650 \mu \mathrm{L} \mathrm{min}{ }^{-1}\end{array}$ \\
\hline $\begin{array}{l}\text { lifetime of MBs } \\
\text { (without adding } \\
\text { SiQD): }\end{array}$ & $35.0 \pm 4.0 \mathrm{mins}$ & $20.0 \pm 2.0 \mathrm{mins}$ & $5.0 \pm 1.0 \mathrm{mins}$ & $20.0 \pm 1.0 \mathrm{mins}$ & $15.0 \pm 4.5 \mathrm{mins}$ \\
\hline
\end{tabular}




\section{Multi-Layer Capsules}

(prepared using electrohydrodynamics)

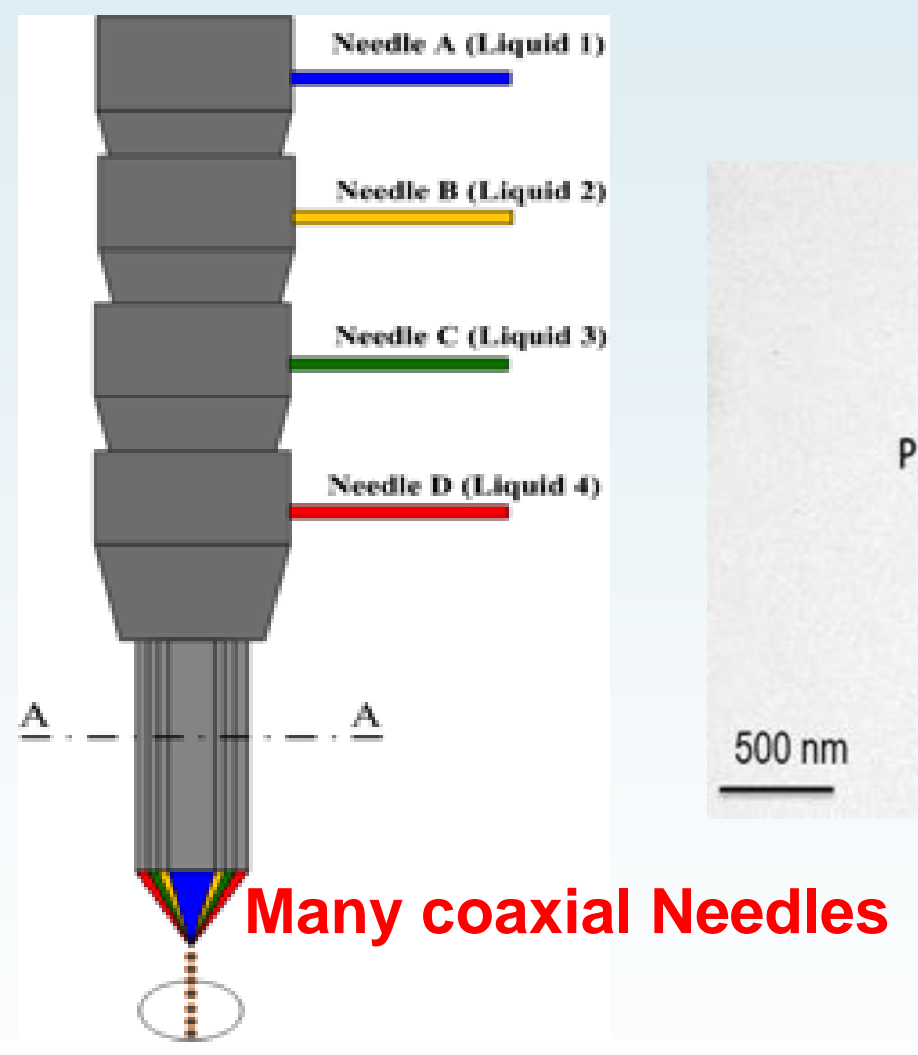

VENTURE PRIZE 2010

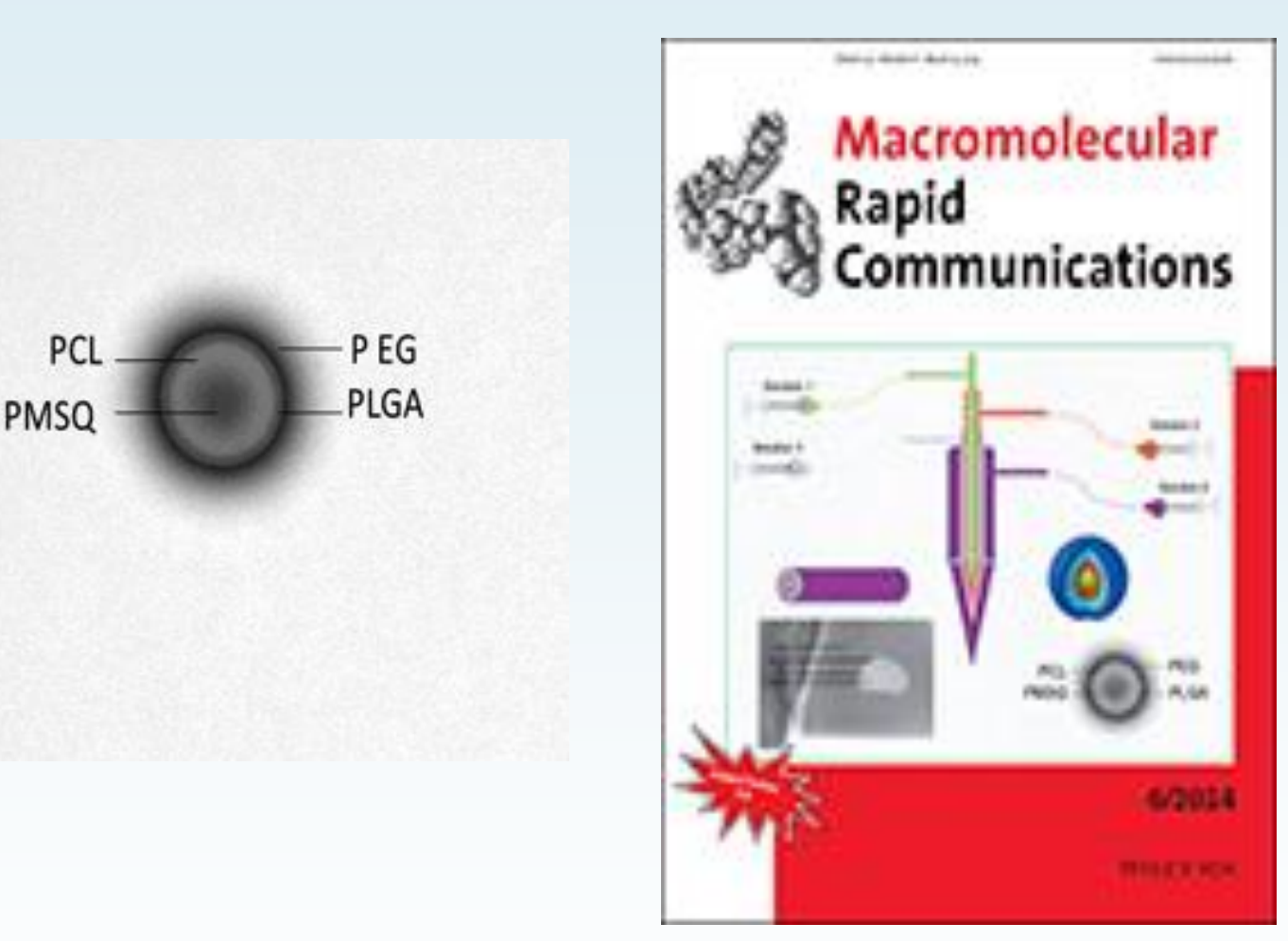

Labbaf S, Ghanbar H, Stride E, Edirisinghe M. Preparation of multilayered structures using a novel fourneedle coaxial device. Macromolecular Rapid Communication 2014 35: 618-623 (front cover article)

UK Patent Application No. 1102148.2 PCT filed: 08Feb 2012 USA Patent Application 13/984345 


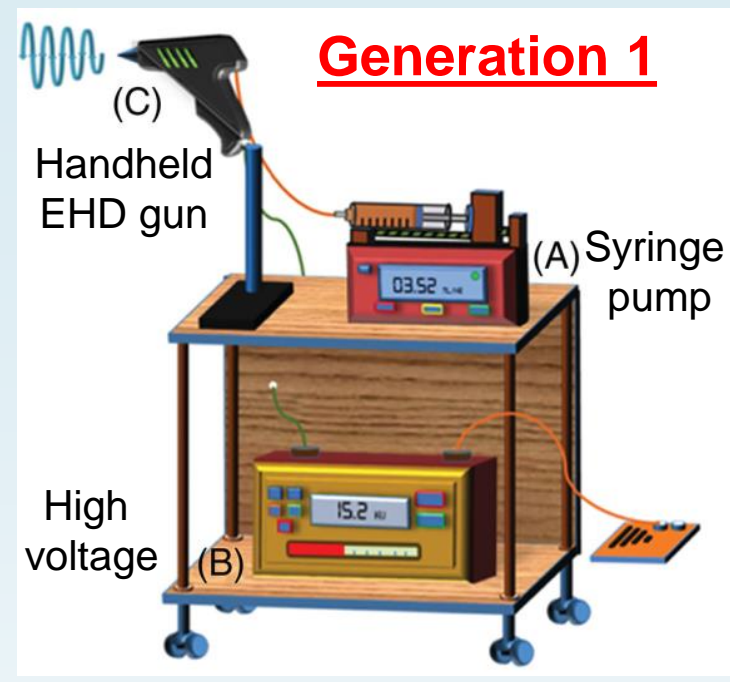

Sofokleous, P.; Stride, E.; Bonfield, W.;

Edirisinghe, M. Mater. Sci. Eng. C Mater. Biol. Appl. 2013, 33 (1), 213-223.
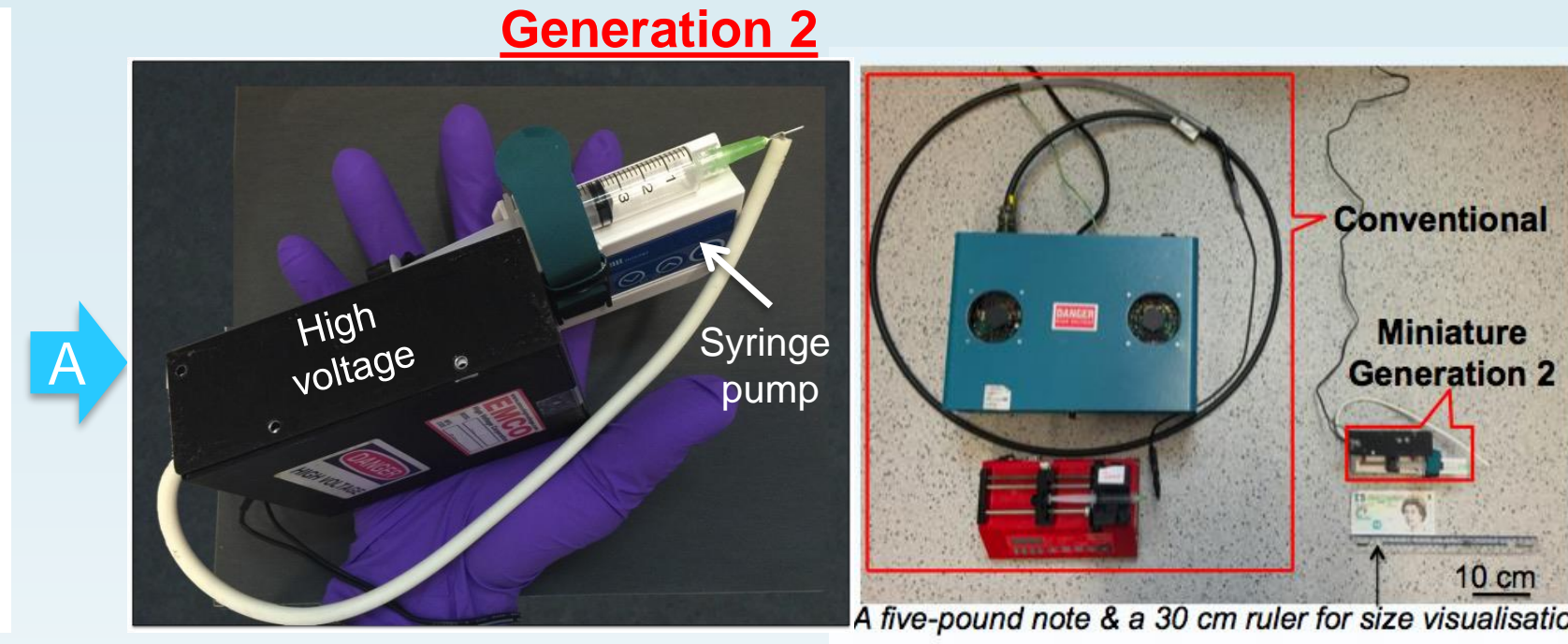

F. Brako, C.J. Luo, D.Q.M. Craig, M. Edirisinghe. Macromolecular Materials and Engineering, 2018, 303 (5), 1700586.

\section{Generation 3}

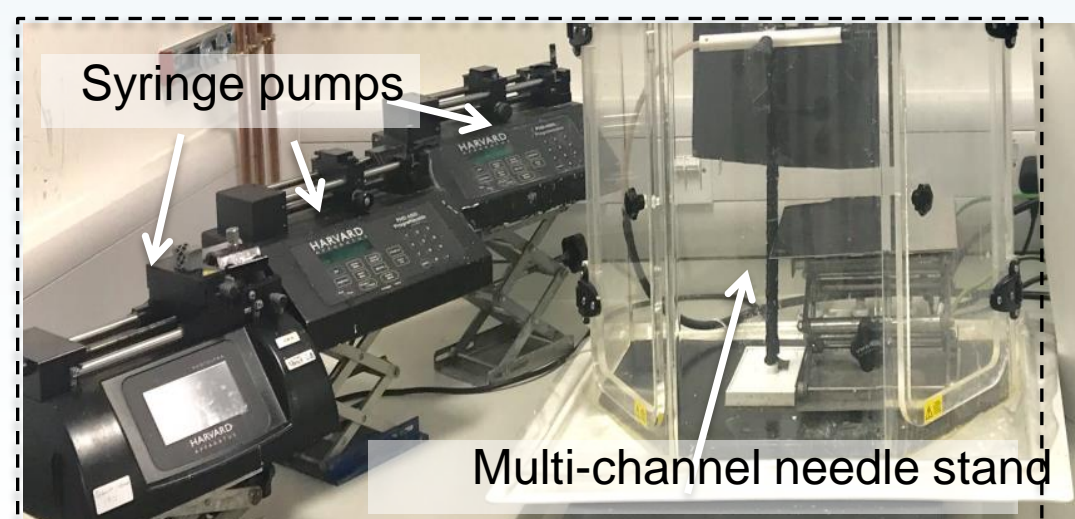

High voltage

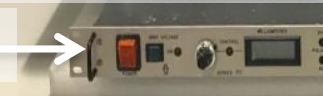

Miniature

Generation 3 of

same

performance

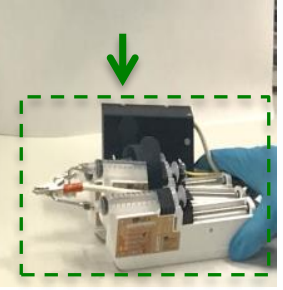

Generation 4

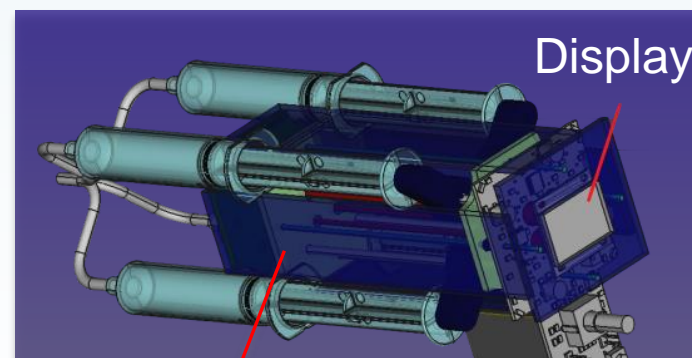

Precision syringe pumps User control board

High voltage

Power converter 
EPSRC grant EP/L023059/1: Exploitation of Pressurised Gyration as an Innovative Manufacturing Route for Nanofibrous Structures. Industrial Support: BASF, Astra Zeneca

(Collab: Professor Duncan Craig, UCL School of Pharmacy)
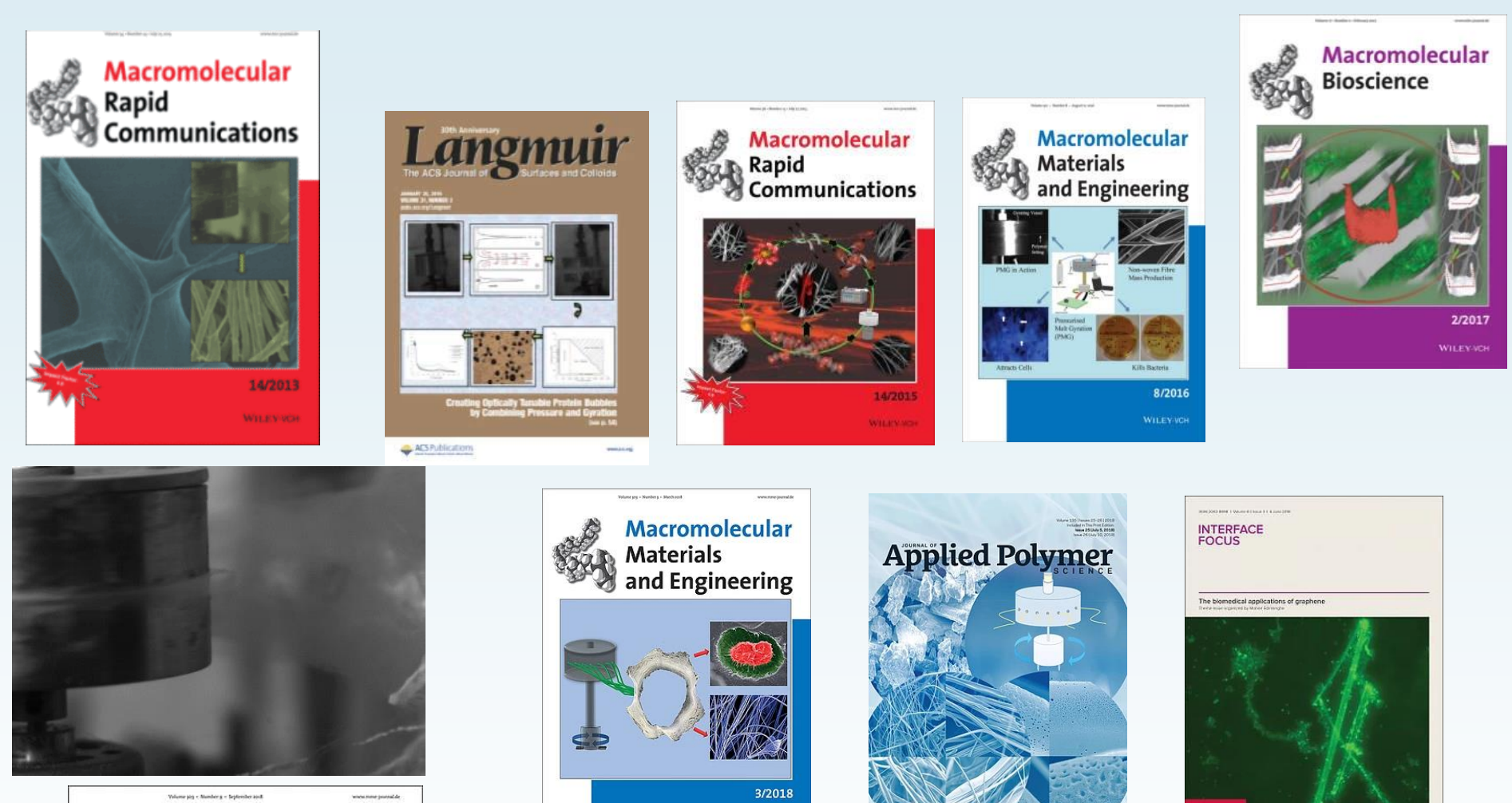

Macromolecular Materials and Engineering

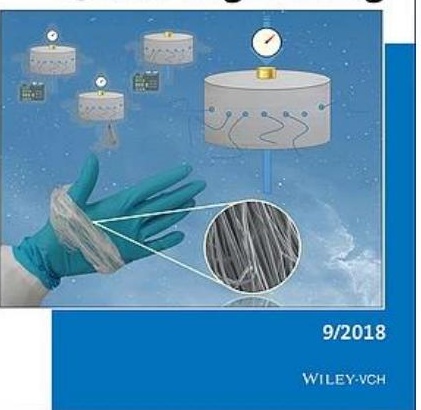

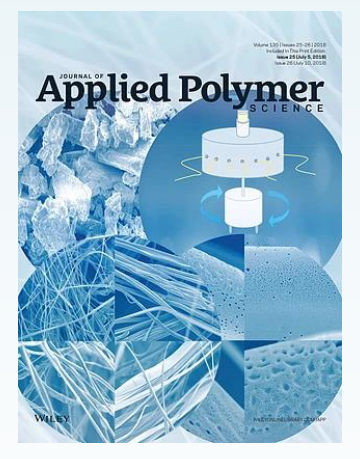

Invited Feature: 2018

Featured in Advanced Science News July $23^{\text {rd }} 2018$

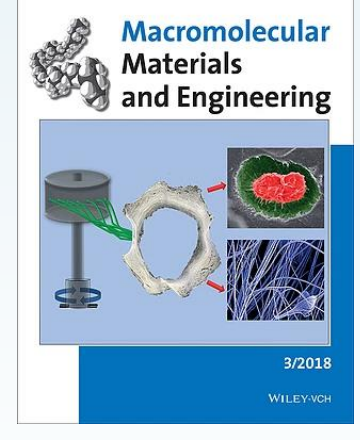

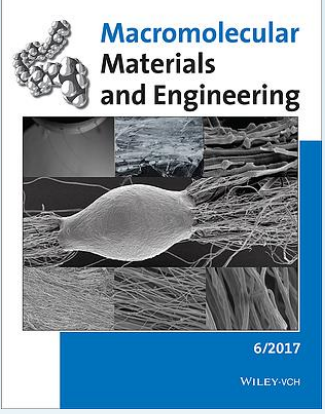

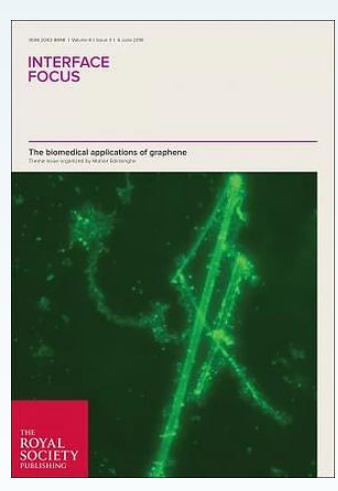

Macromolecular

Materials

and Engineering

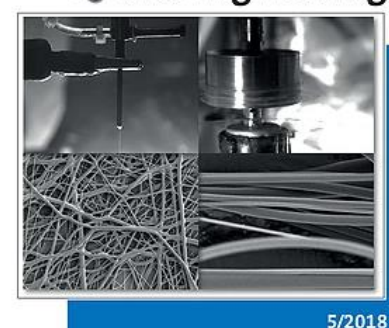

BEST OF MACROS 2018

\section{BEST OF MACROS 2019}




\section{EP/S016872/1:}

\section{Creation and Exploitation of Pressurised Gyration to Manufacture Core-Sheath Structures}

Mahalingam, S; Homer-Vanniasinkam, S; Edirisinghe, M; (2019) Novel pressurised gyration device for making core-sheath polymer fibres. Materials \& Design , 178 , Article 107846. 10.1016/j.matdes.2019.107846.

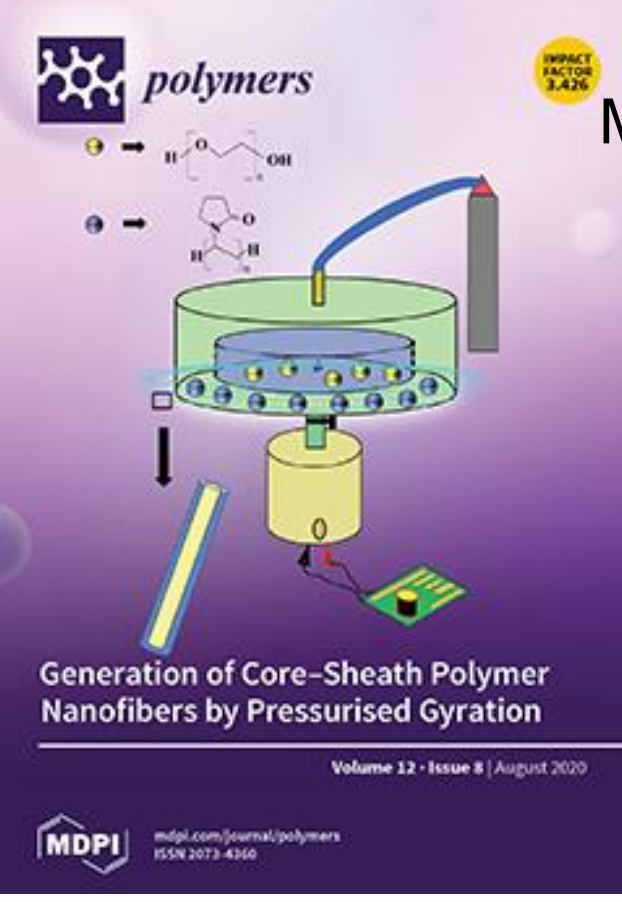

Polymers 2020, 12, 1709; doi:10.3390/polym12081709 Mahalingam, S; Huo, S; Homer-Vanniasinkam, S; Edirisinghe, M

Current methodologies and approaches for the formation of core-sheath polymer fibers for biomedical applications

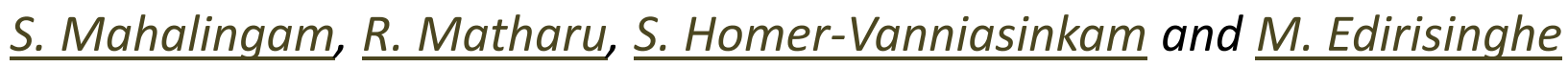

Altmetric

Applied Physics Reviews 7, 041302 (2020); https://doi.org/10.1063/5.0008310 


\section{EPSRC Grants: EP/N034228/1_\& EP/N034368/1}

Antimicrobial filters for hospital air and water system

\section{$\stackrel{ \pm}{\prime} \mathrm{CL}_{\mathbf{L}}$}

(Collab: Dr Lena Ciric UCL Eng Civil Eng. (microbiologist) \& UoH Eng.)

Mark-II of device (2015-16)
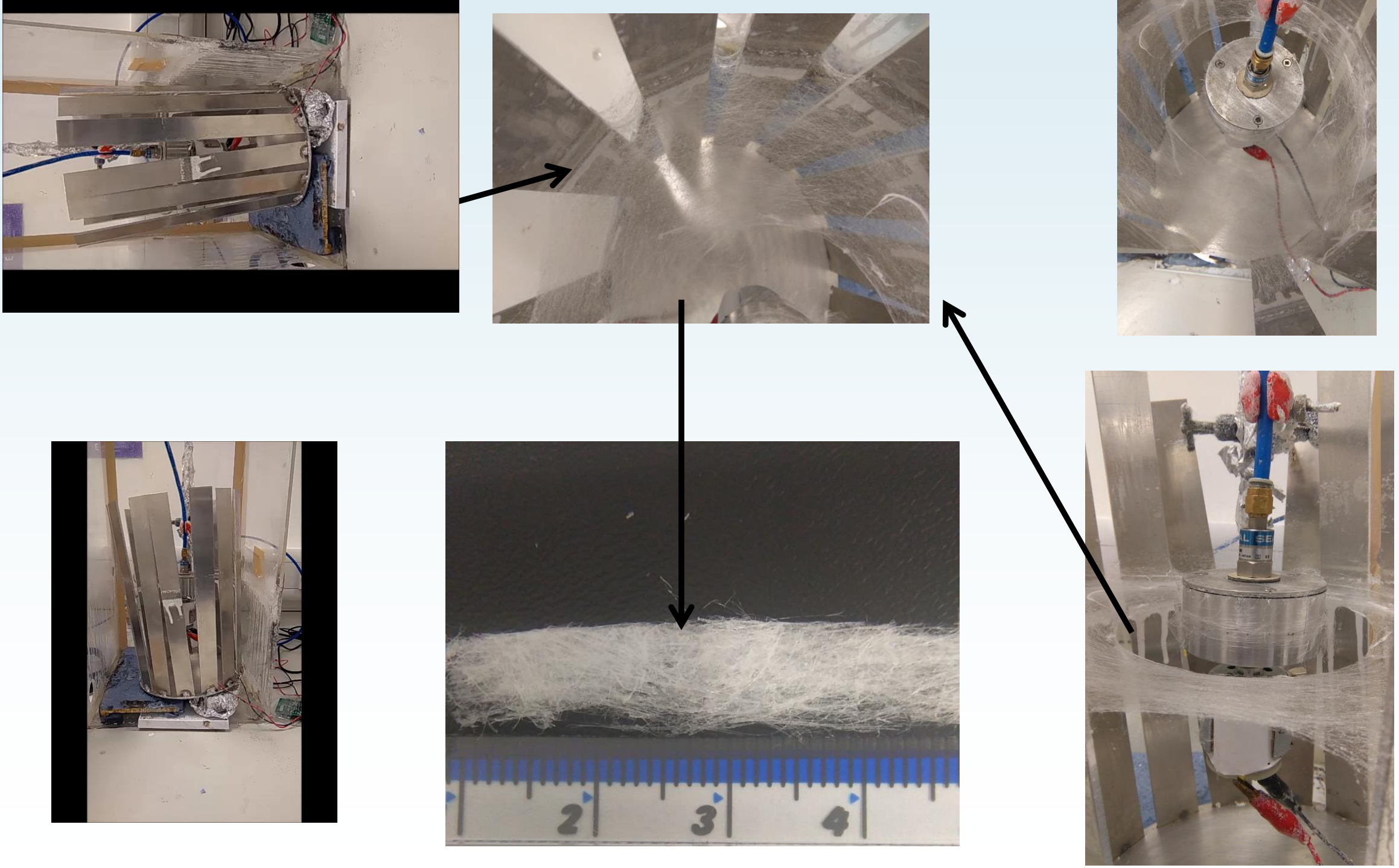


\section{Novel Antimicrobial Filters}

A number of nanoparticle preparations were assessed for their antimicrobial properties.
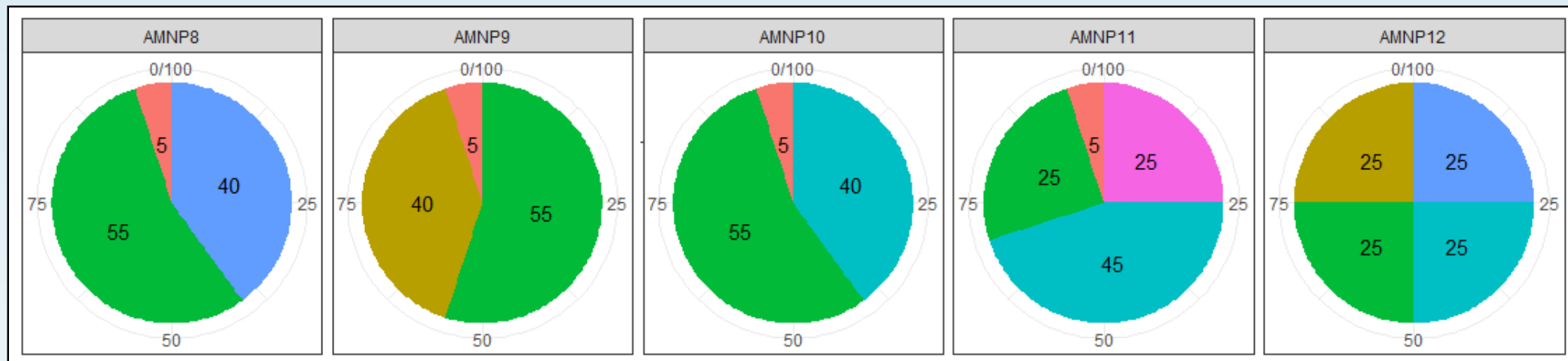

NP

$\mathrm{Ag}$

CuAg

CuO rods CuO spheres CuZn wC

\section{Nanoparticle Combinations}

Nanocomposite filters were developed using pressurised gyration, during which poly(methylmethacrylate) (PMMA) solutions were loaded with antimicrobial nanoparticles and processed into nanofiber meshes.
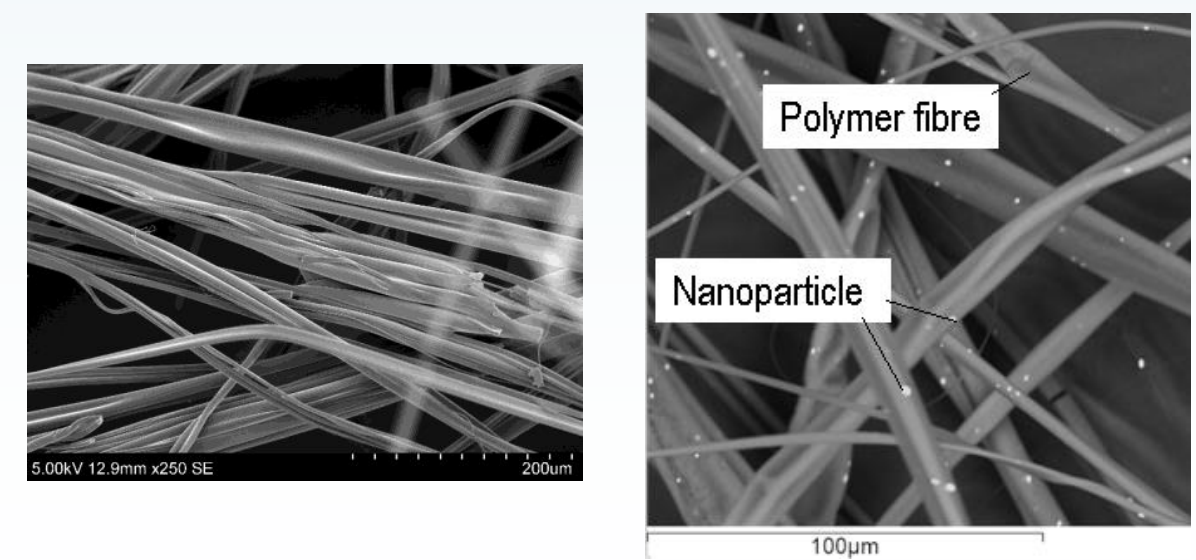

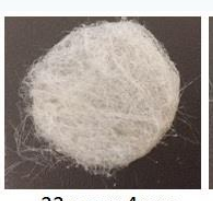

$33 \mathrm{~mm} \times 4 \mathrm{~mm}$

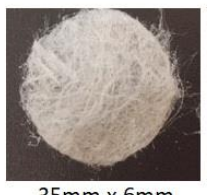

$35 \mathrm{~mm} \times 6 \mathrm{~mm}$

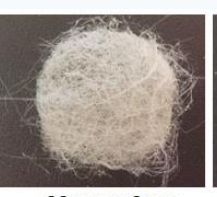

$32 \mathrm{~mm} \times 3 \mathrm{~mm}$

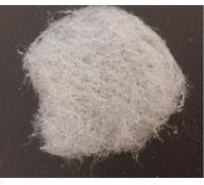

$32 \mathrm{~mm} \times 5 \mathrm{~mm}$

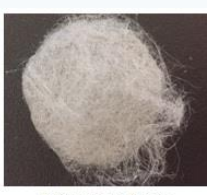

$34 \mathrm{~mm} \times 4 \mathrm{~mm}$

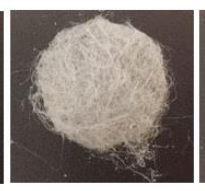

$33 \mathrm{~mm} \times 4 \mathrm{~mm}$

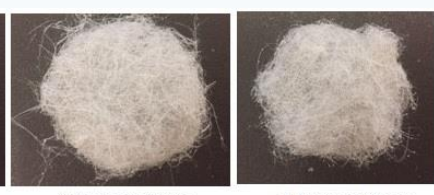

$35 \mathrm{~mm} \times 3 \mathrm{~mm}$

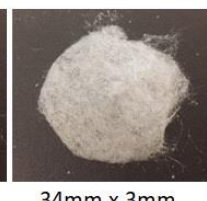

$37 \mathrm{~mm} \times 6 \mathrm{~mm}$

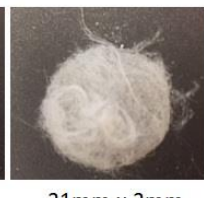

$31 \mathrm{~mm} \times 3 \mathrm{~mm}$

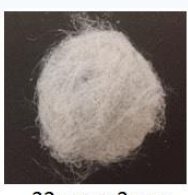

$32 \mathrm{~mm} \times 3 \mathrm{~mm}$

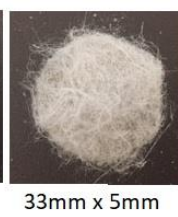




\section{Novel Antimicrobial Filters}

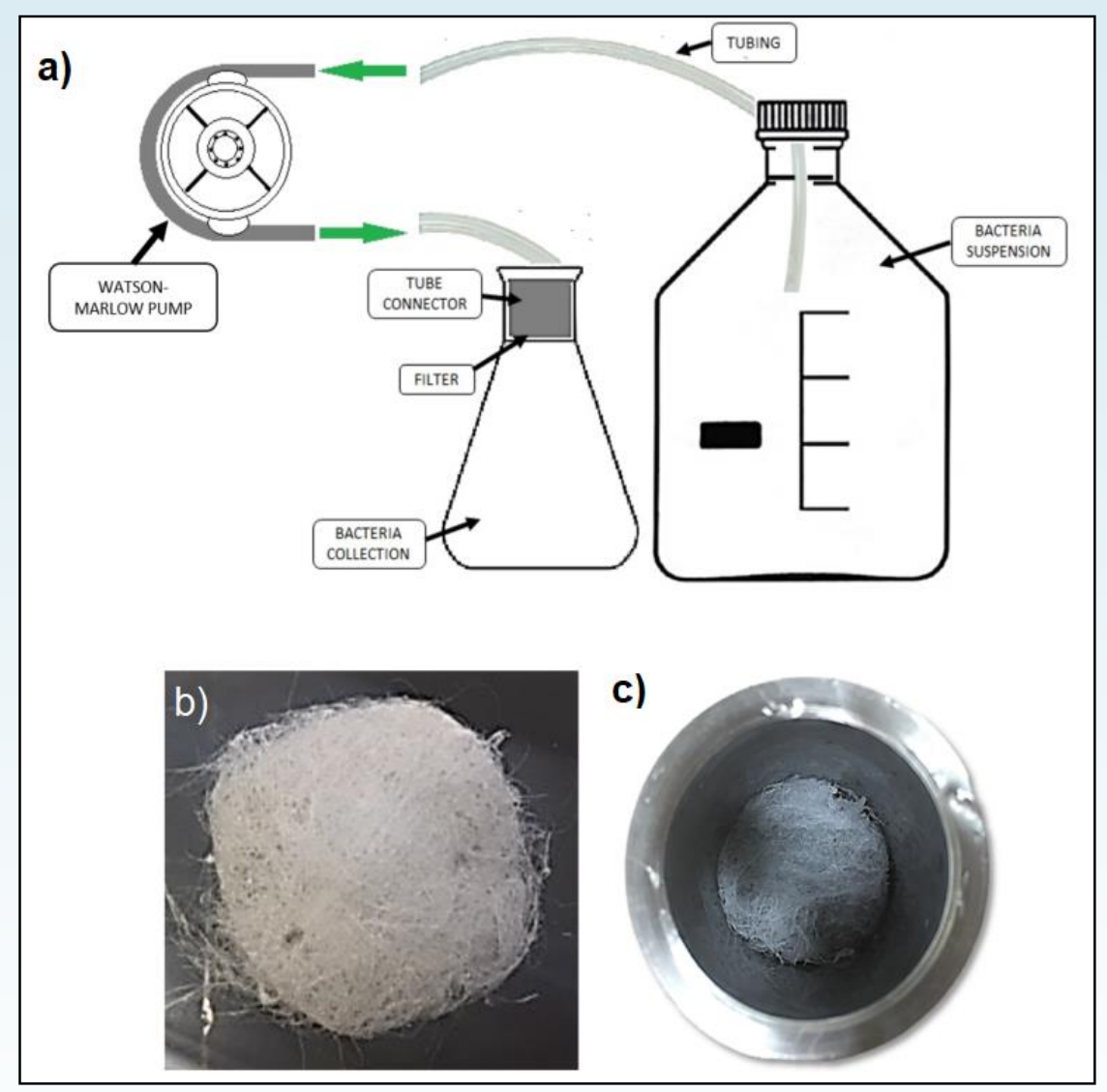

Filters were tested using phosphate buffered saline solution spiked with high concentrations of Pseudomonas aeruginosa and Staphylococcus aureus. The bacterial suspensions were passed through a peristaltic pump at $500 \mathrm{~mL} \mathrm{~min}^{-1}$ to simulate standard UK tap pressure.

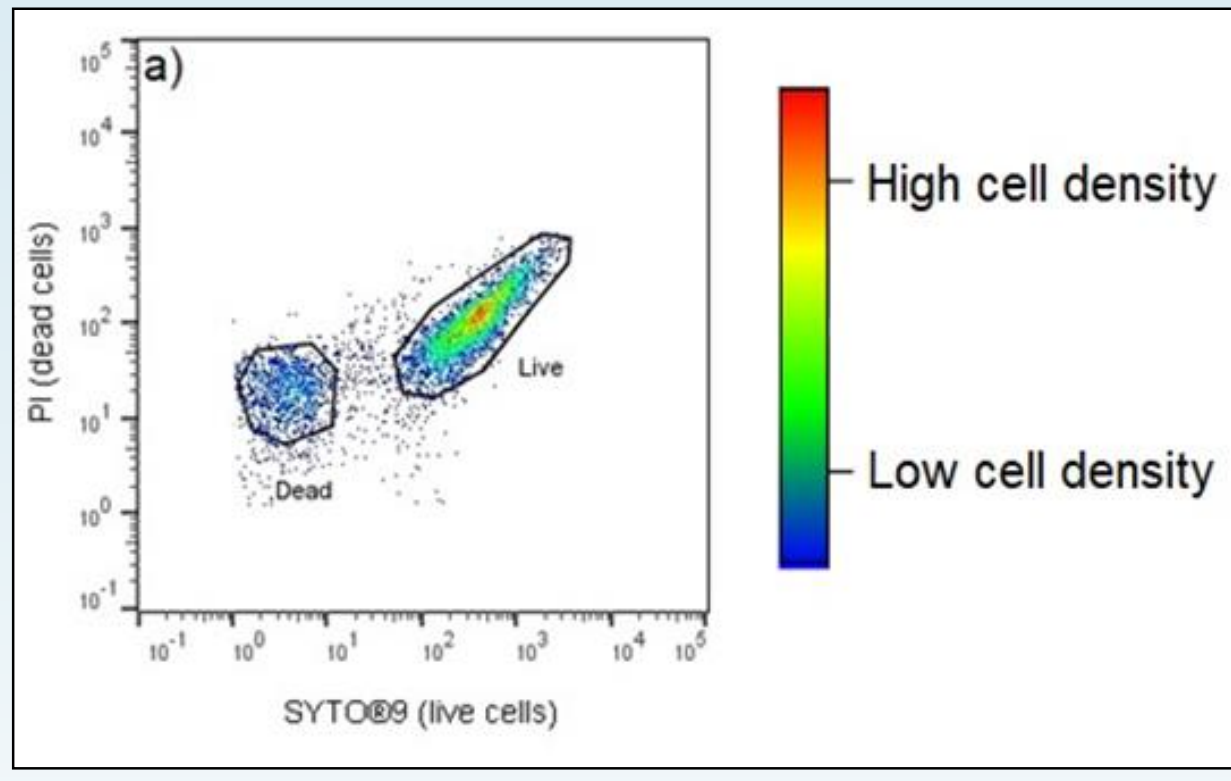

The viability of bacterial populations were quantified and analysed using flow cytometry to determine live and dead cells after filtration.

Project Partners:

GAMA Healthcare Ltd Intrinsiq Materials Limited

Pall Corporation

Pathogen Solutions

Professor John Oxford 


\section{Novel Antimicrobial Filters}

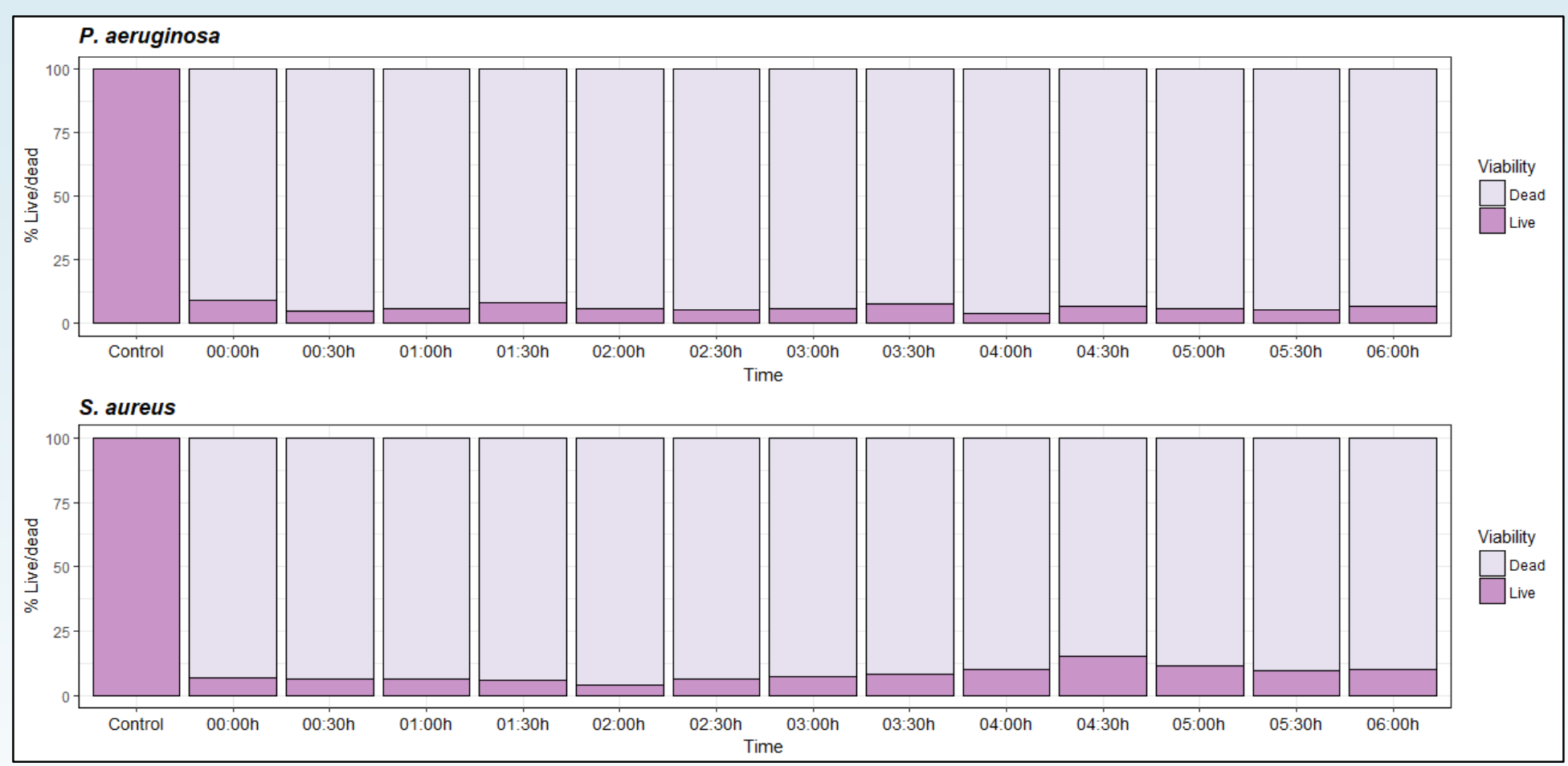

AMNP8.1 filters showed reproducible results upon reuse every 30 minutes for 6 hours.

Project Partners:

GAMA Healthcare Ltd Intrinsiq Materials Limited

Pall Corporation

Pathogen Solutions

Professor John Oxford 


\section{EXPLOITING GRAPHENE AND ITS DERIVATIVES IN BIOMED. ENG. $=[\mathrm{J}$}

The Effect of Graphene-Poly(methyl methacrylate) Fibres on Microbial Growth.

Graphene nanoplatelets (GNPs) are the most recently discovered carbon-based nanomaterial. They are the two-dimensional counterpart of carbon nanotubes and are composed of a single layer of sp2 hybridized carbon atoms arranged in a regular hexagonal lattice.

The microbial properties of a novel class of ultra-thin PMMA fibres containing 2,4 and 8 wt\% of (GNPs) were studied. A series of polymer solutions loaded with GNPs were prepared and processed into continuous, tubular and smooth nanofiber meshes using pressurised gyration. As GNP concentration increased, the average fibre diameter increased from $0.75 \mu \mathrm{m}$ to $2.71 \mu \mathrm{m}$.

Gram-negative bacteria Escherichia coli and Pseudomonas aeruginosa were used to investigate the bacterial properties of the composite fibres. Pure PMMA fibres were used as the control. The presence of 2 and 4 wt\% GNP loaded fibres promoted microbial growth, whilst 8 wt\% GNP loaded fibres showed antimicrobial activity.

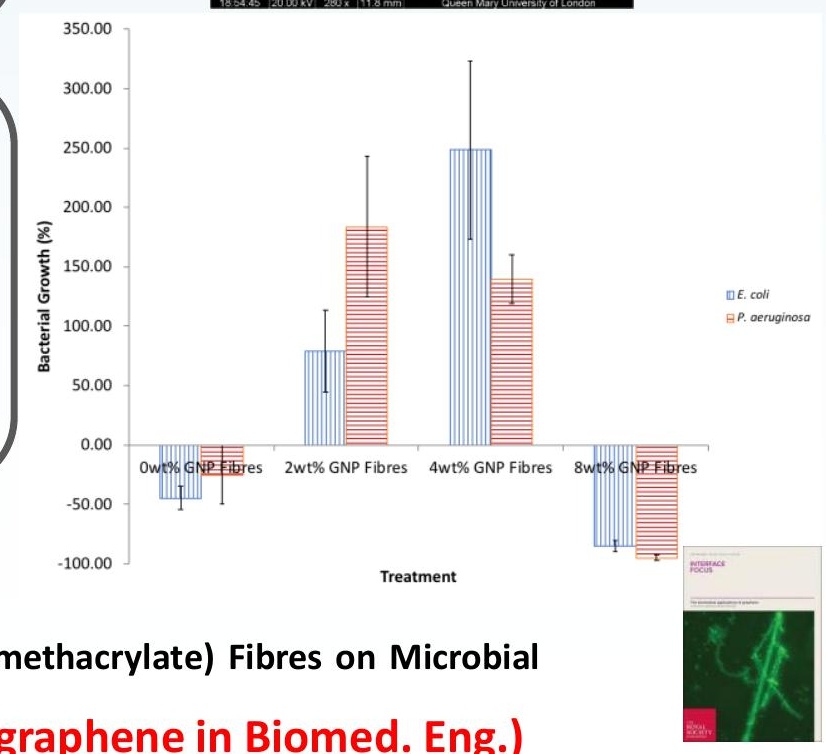

Matharu, R. K., Porwal, H., Ciric, L. and Edirisinghe, M. (2018). The Effect of Graphene-Poly(methyl methacrylate) Fibres on Microbial Growth. Roval Society Interface Focus, 8, 20170058; doi:10.1098/rsfs.2017.0058. (Special issue on graphene in Biomed. Eng.) 

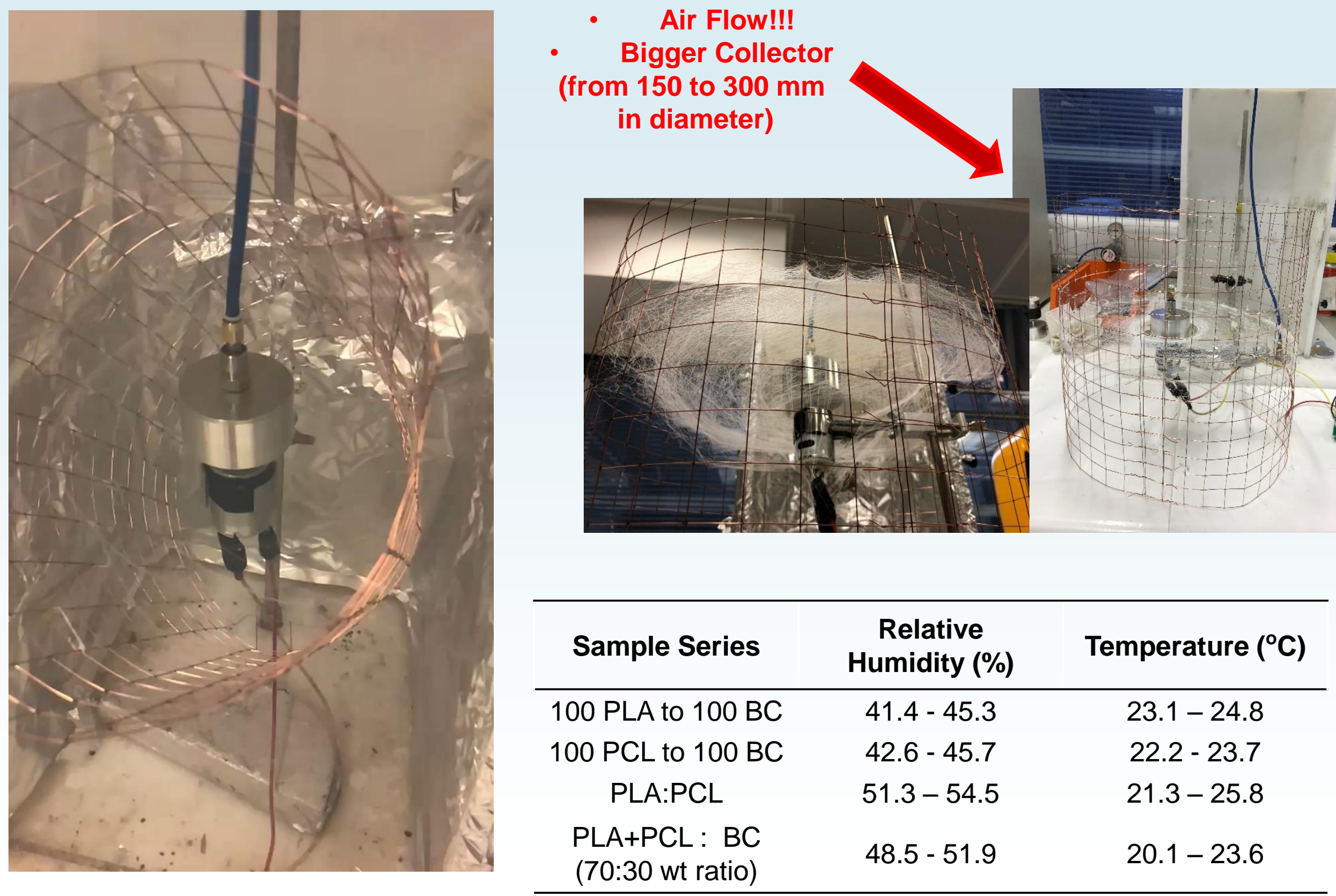

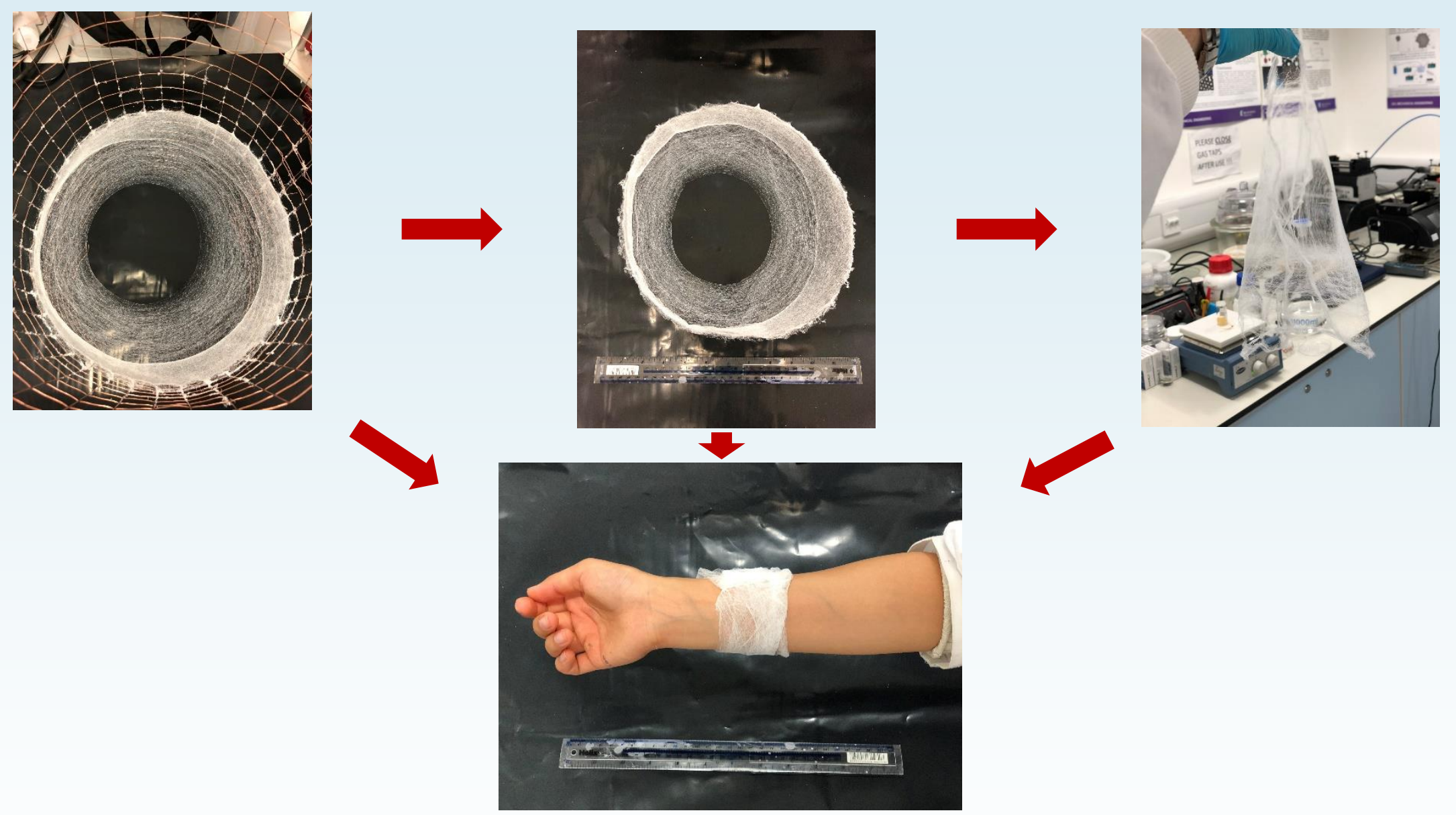

PLA:PCL samples from collector to bandage form 


\section{PEO 15 wt. $\%$ + HA 30 wt. $\%$ at 36000 rpm and $0.3 \mathrm{MPa}$}
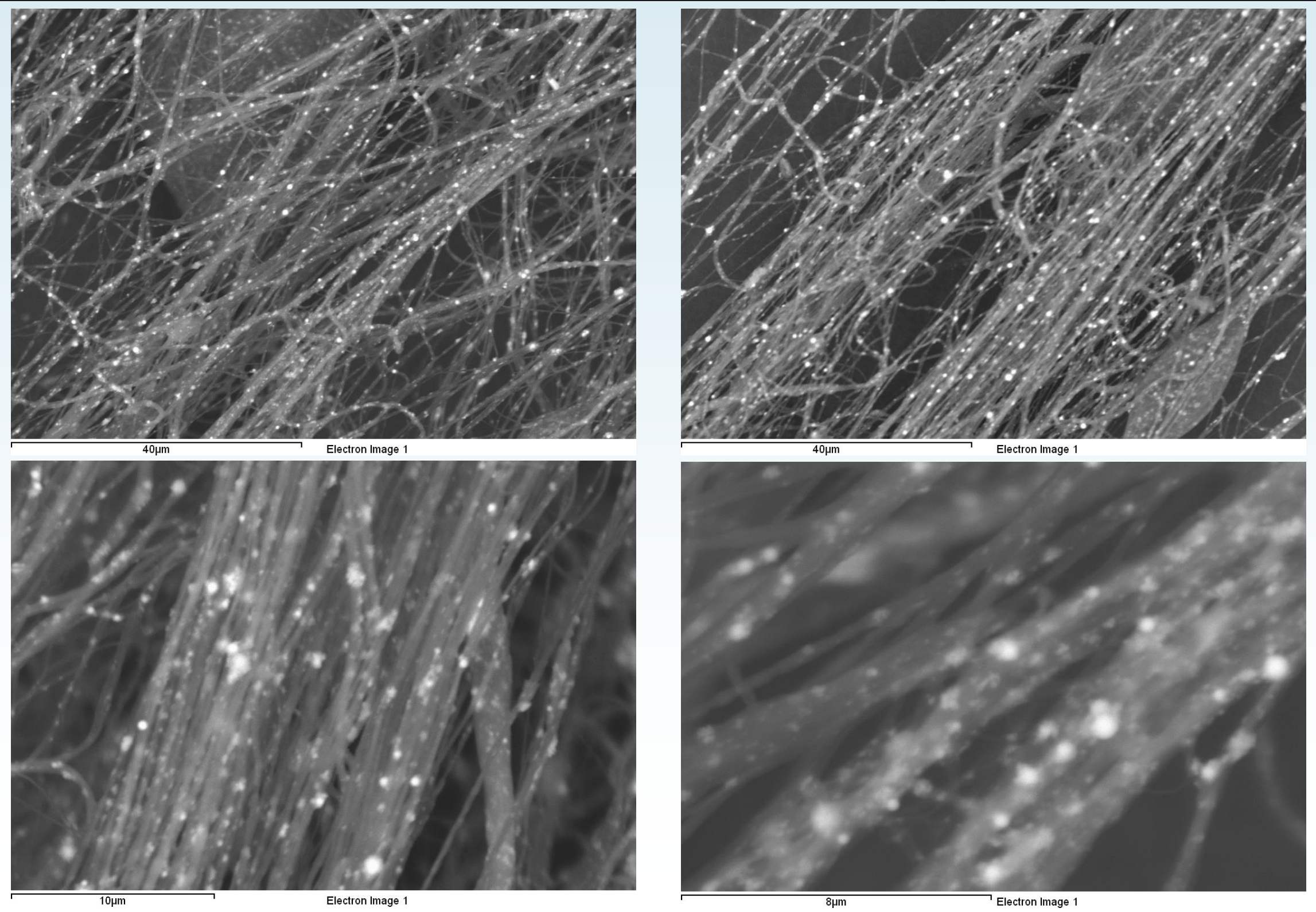


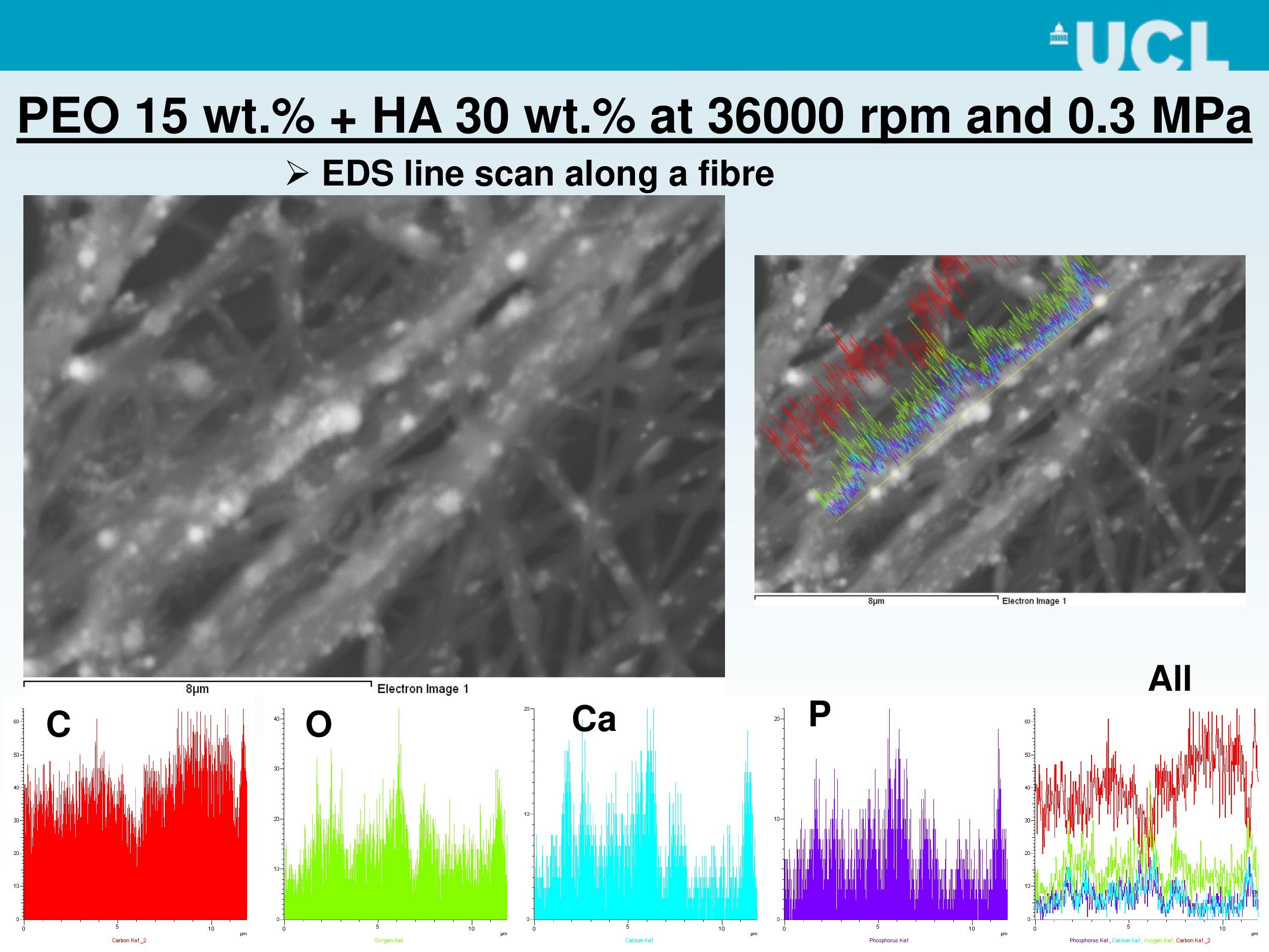




\section{$\pm J_{1} C_{L}$}

\section{Electrospinning}

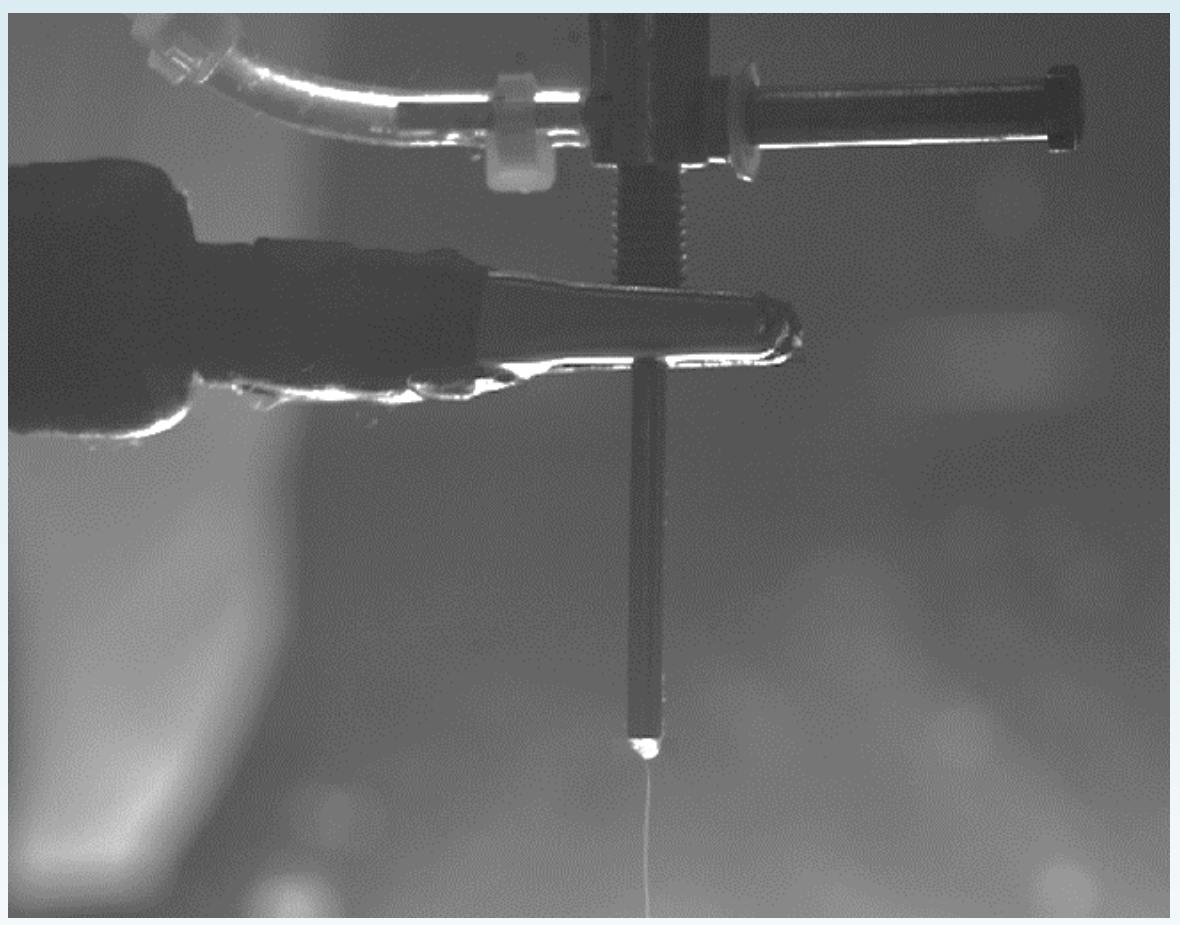

- Electric field overcomes surface tension of polymer solution which allows for a highly tuneable fibre production (voltage increase very incremental)

- Can create very fine fibres with wide range of biomedical applications

- Due to electric field, polymer solution must be conductive, which limits usage of various polymer systems

\section{Pressurised Gyration}

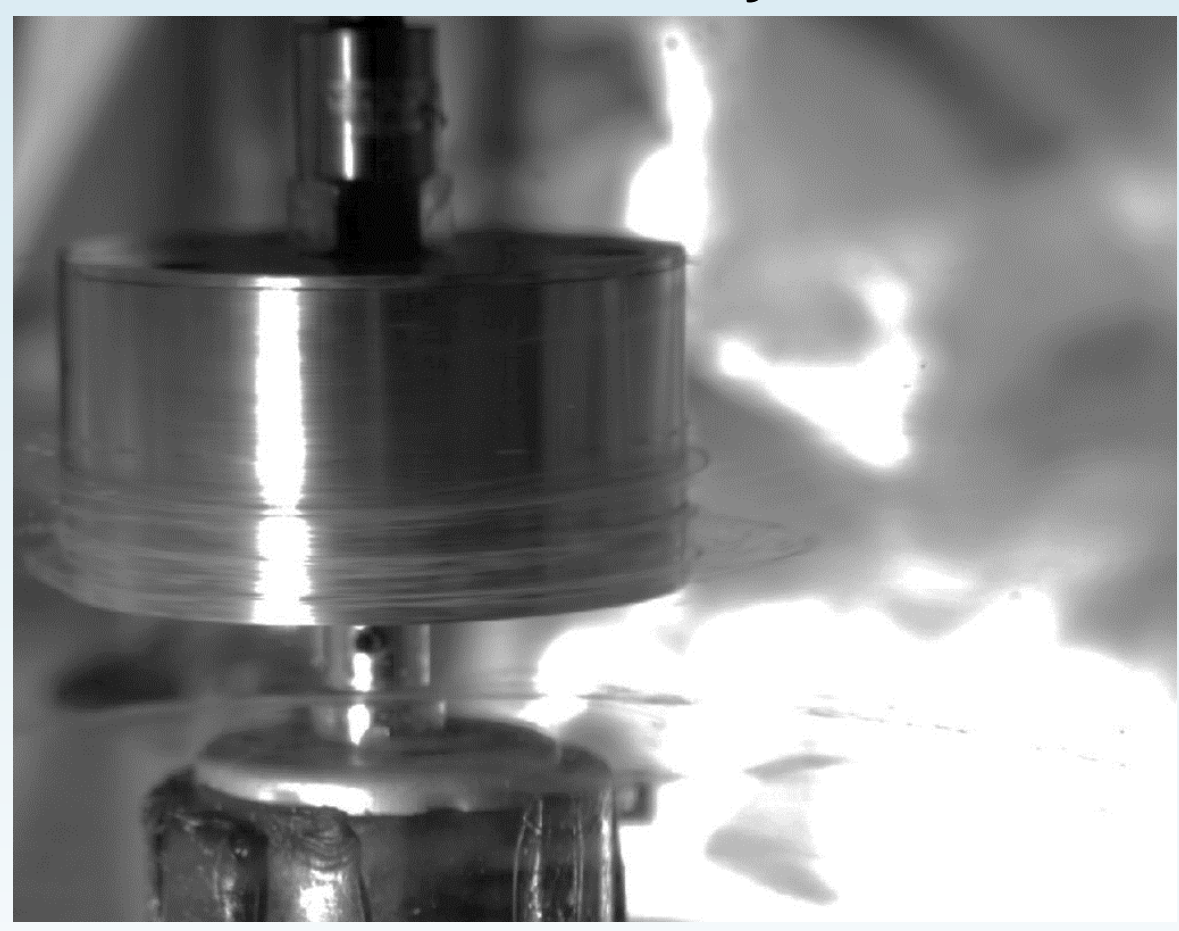

- Centrifugal force and applied gas pressure overcome surface tension of solution which allow for a large range of materials to be used, in solution form or otherwise

- Very rapid fibre production rate with great potential for scale-up

- The full potential of this technology has not yet reached 


\section{Differences in Polymer Preparation}

\section{Electrospinning}

Pressurised Gyration
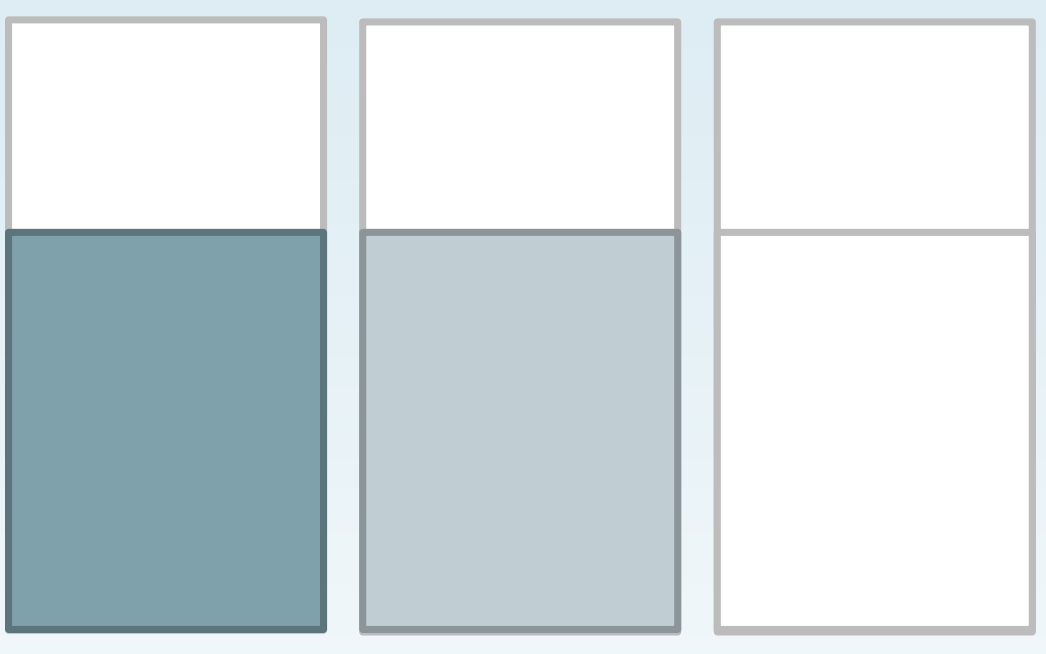

- Polymer solution must be prepared by dissolving a polymer within a solvent

- Polymer solution must be conductive in order to form fibres

- Solution must be homogenous otherwise it can effect the fibre formation

- Non-dissolved solutions can cause needle and pipe clogging and potentially damage setup

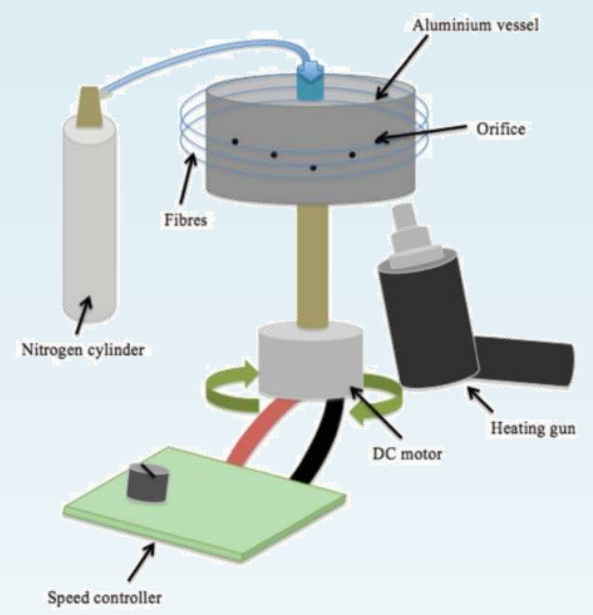

- Polymer solution can be prepared just like with electrospinning

- Non-homogenous solution can be spun as vessel is large and creates mixing during spinning

- Polymer melts can also be spun using melt gyration

- Materials in vessel can be in different phases, but can still form fibres

- Thick and viscous solutions can be spun which can be a problem with EHD 


\section{Electrospinning}

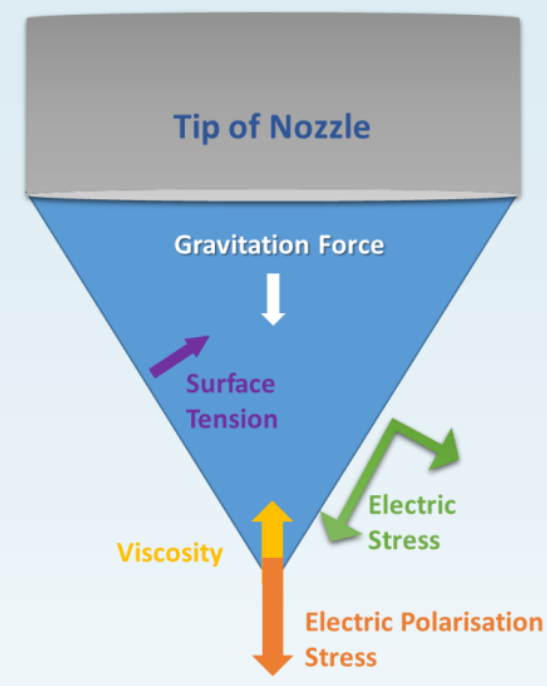

- Voltage can be adjusted very incrementally to give great control over final fibre morphology

- Flow rate is carefully governed to suit desired application and fibre size

- Collection distance can be altered to optimise fibre production by controlling fibre drying times

- Needle size can also have an effect on fibre production and morphology
Pressurised Gyration
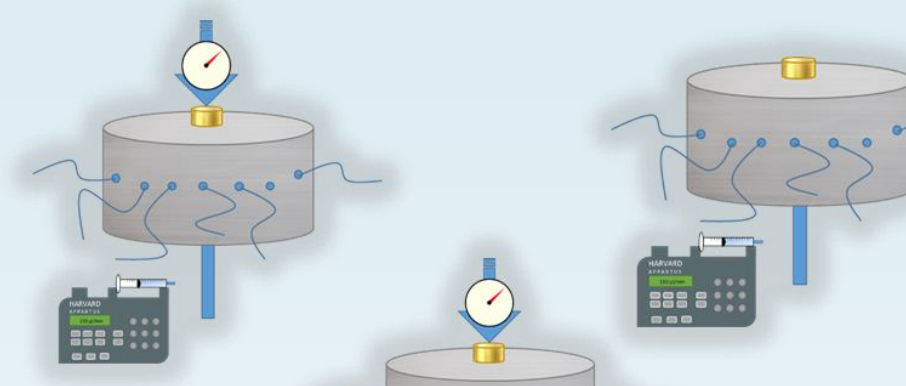

- Rotation speed influences centrifugal force and can be adjusted to control fibre morphology

- Applied gas pressure can also be increased to reduce fibre diameter, and control bead production

- Collection distances and setups do influence fibre structure

- Relative humidity can be used to regulate drying times and thus fibre morphology

- Melt temperature and infusion rate can further used to regulate fibre production 


\section{Differences in Fibre Production Rate}

\section{Electrospinning}

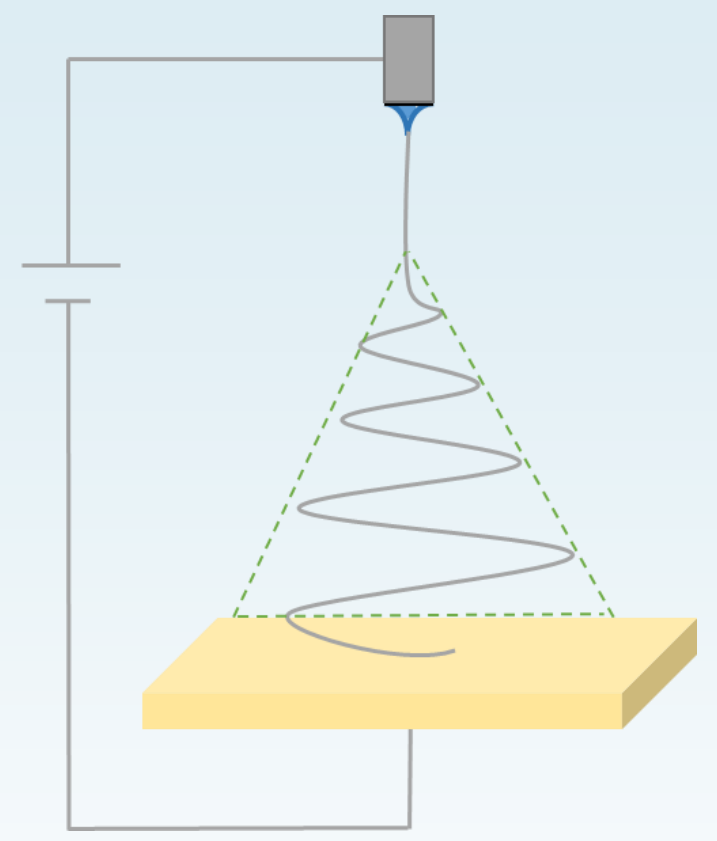

- Typical flow rates are $50-150 \mu \mathrm{L} / \mathrm{min}$ in a single needle setup

- Typical fibre production in 1 hour is approximately $\mathbf{0 . 6}$ grams of fibre for normal single-needle nanofibre setups

- Can be scaled up with multiple needle set-ups and advanced needle and collector devices which minimise solutionrelated problems
Pressurised Gyration

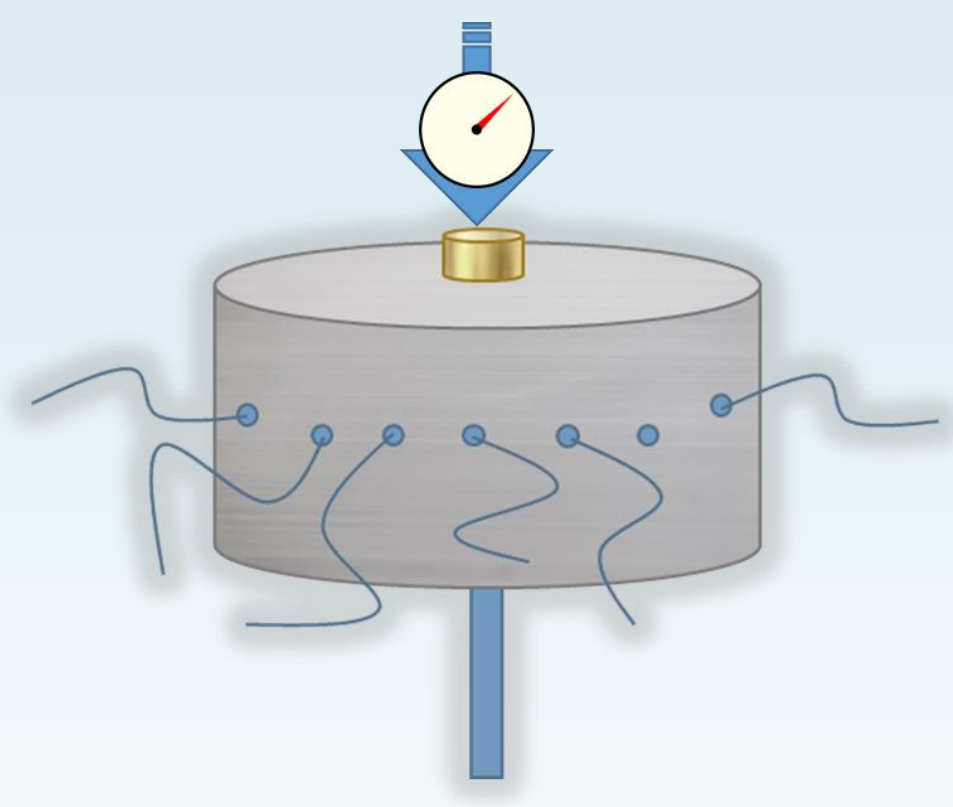

- $5 \mathrm{~mL}$ of polymer solution can be produced into fibres in 15 seconds

- Typical fibre production rate in 1 hour is approximately $\mathbf{1 2 0}$ grams

- Infusion gyration can further increase production rate to exceed $6 \mathrm{~kg} /$ hour

- Just like electrospinning, multiple gyration pot setups can be created to increase production rate 


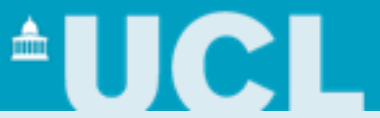

\section{Differences in Fibre Morphology}

Electrospinning

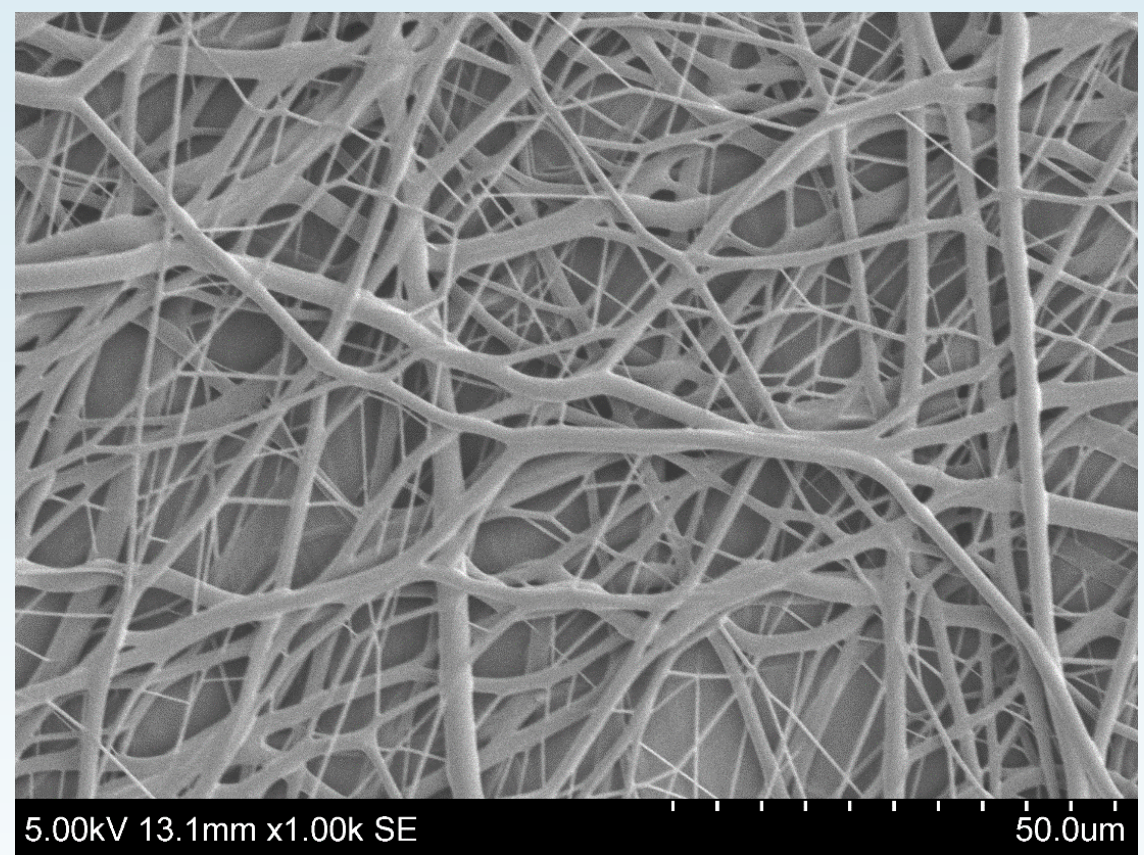

- Without a modified collector electrospun fibres form mesh-like fibres useful in mimicking the ECM

- Increased collection times allow for stacking up of layers to create 3D structures

- Very low fibre diameters can be achieved as low concentration polymers can be used
Pressurised Gyration

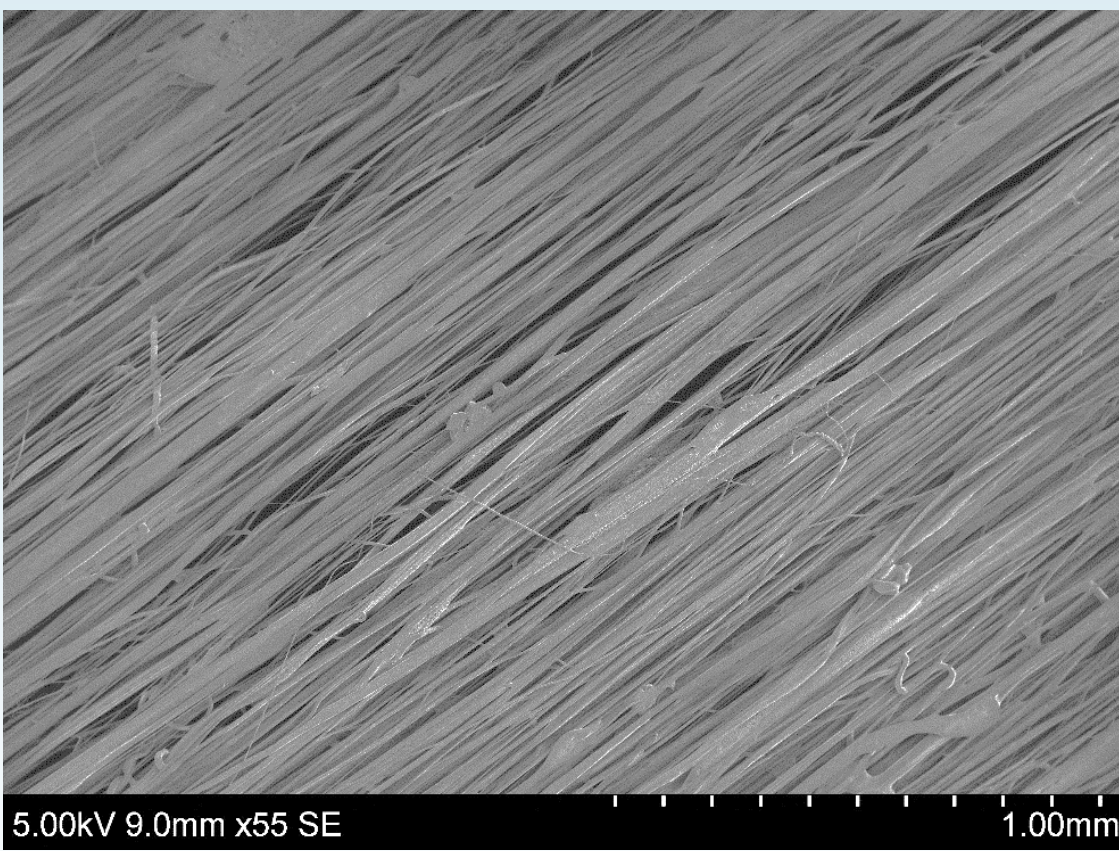

- PG fibres can easily form highly aligned structures suitable for use in neural tissue engineering

- The fibres can be collected into mats, bandages and other shapely materials and used directly as bandages without an additional step

- High production capable of fulfilling demand in medical scenarios 
Delivery

\section{Pressurised Gyration Vs. Electrospinning for Drug Delivery}

Electrospinning PVP-Itraconazole Average Fibre

Diameter: (0.94 $\mu \mathrm{m} \pm 0.34)$

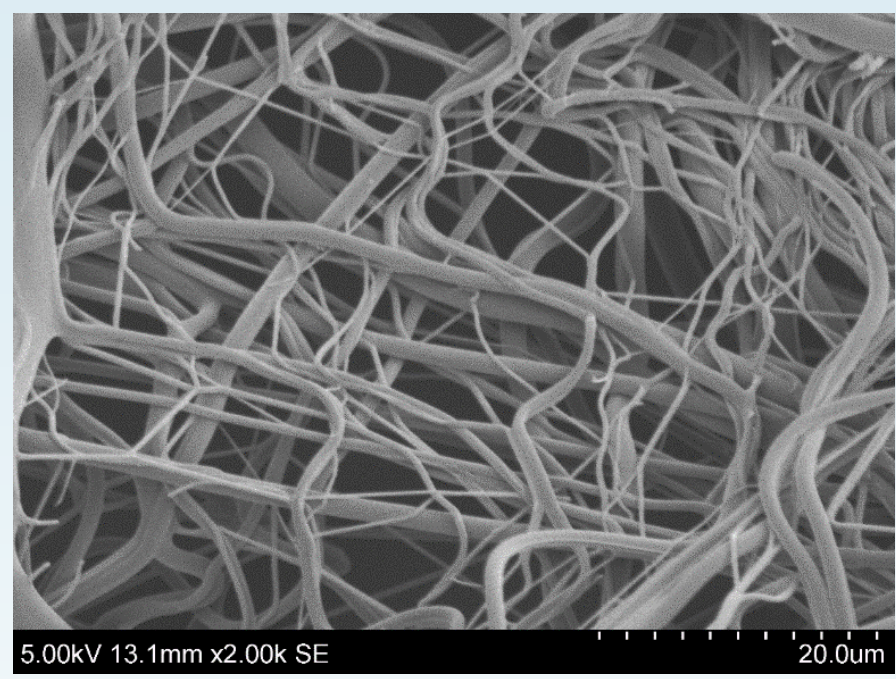

\section{Gyration} PVP-Itraconazole Average Fibre

Diameter: $(1.60 \mu \mathrm{m} \pm 0.87)$
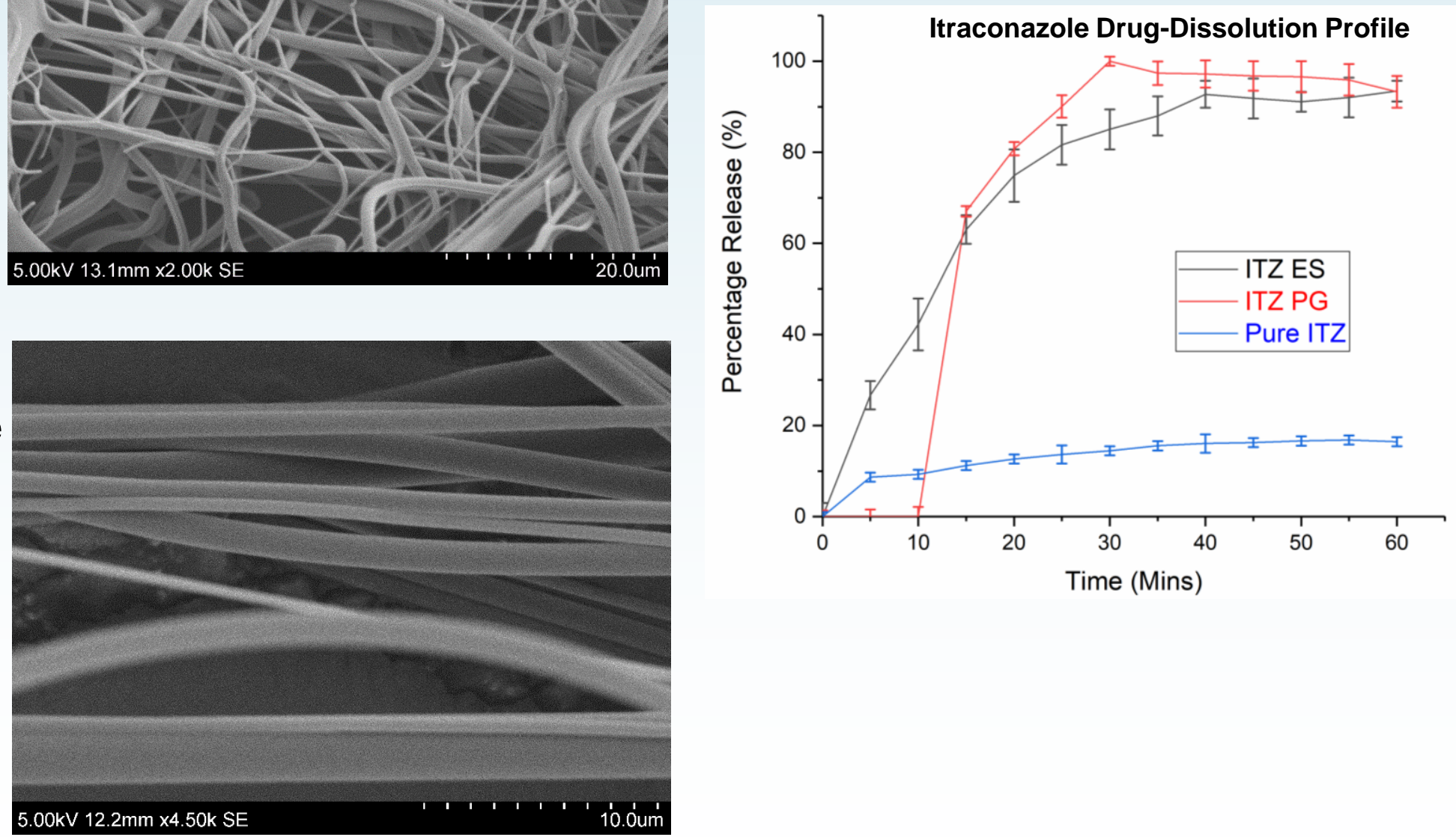

Ahmed, J., R. K. Matharu, T. Shams, U. E. Illangakoon and M. Edirisinghe (2018). "A Comparison of Electric-Field-Driven and Pressure-Driven Fiber Generation Methods for Drug Delivery." Macromolecular Materials and Engineering, 1700577. 


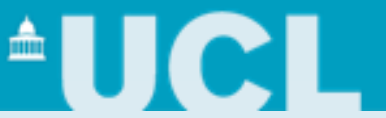

\section{Differences in physical applications}

\section{Electrospinning}

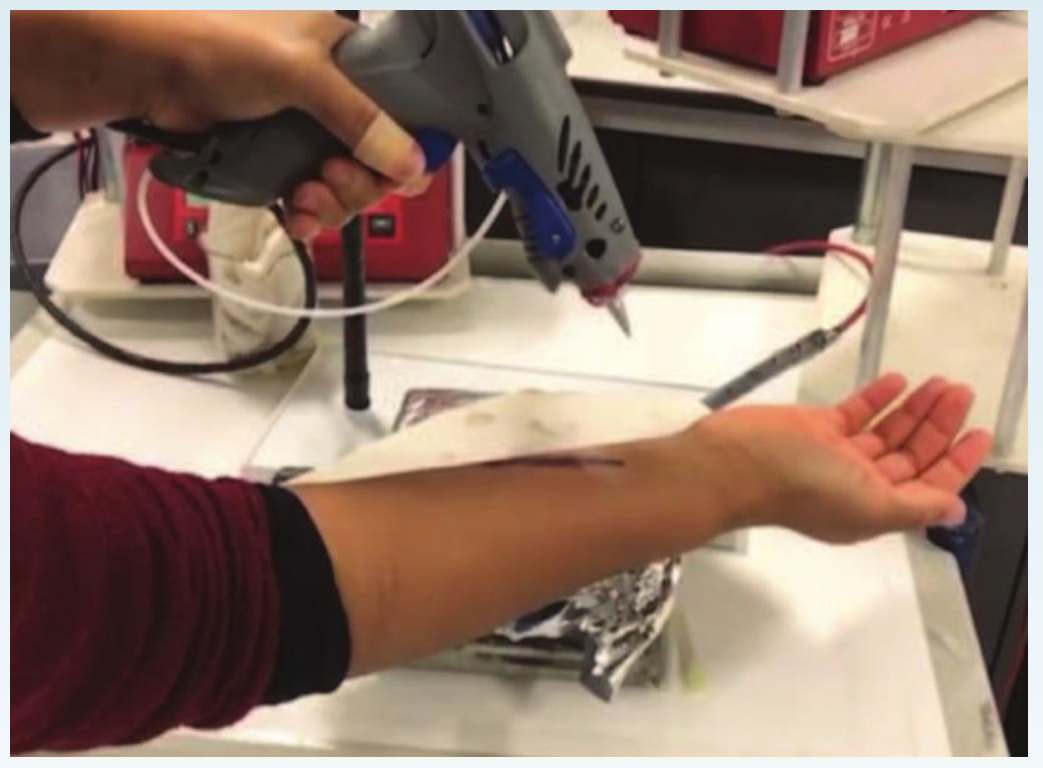

- Can be used to create filters with small mesh sizes that are capable of trapping microbes

- Portable EHD gun can be used to coat a layer of protective fibres directly onto the wound site in an emergency state

\section{Pressurised Gyration}

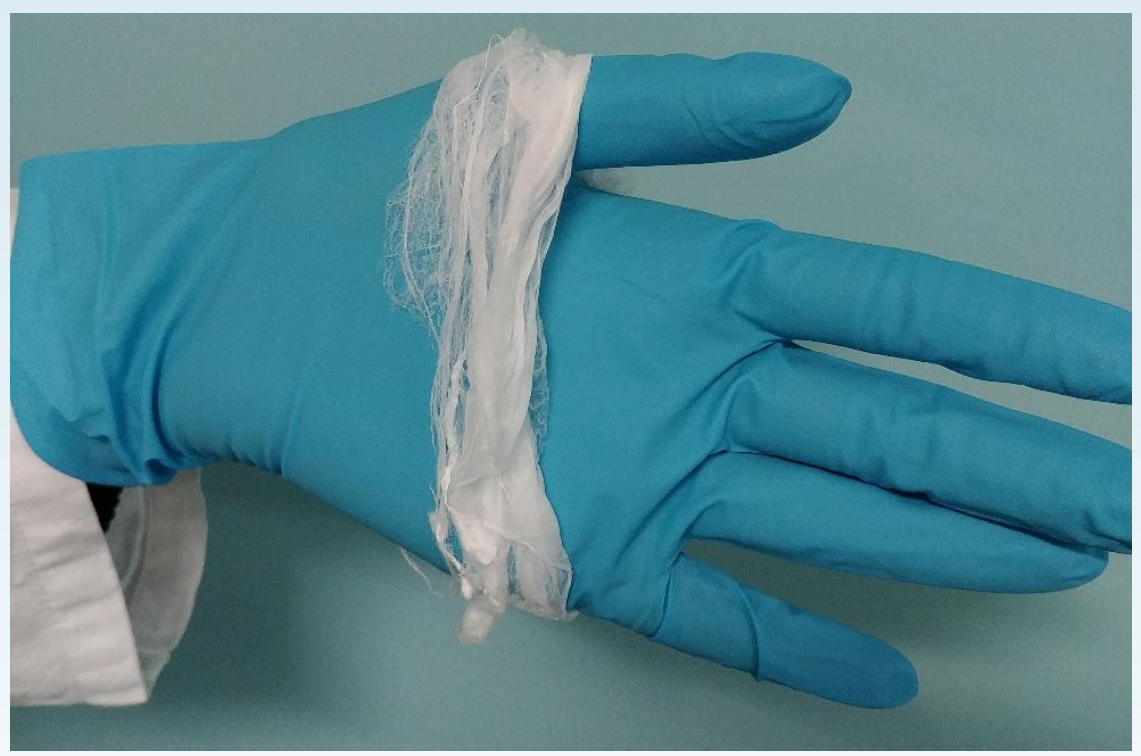

- Rapid spinning process allow for macroscaled materials to be produced fast allowing for use in more physical applications such as wound dressings - As the spinning material does not have to be in a solution, a wide range of antimicrobial and pro wound-healing additives can be incorporated into the bandages

Aydogdu, M.O., et al., Cellular interactions with bacterial cellulose: Polycaprolactone nanofibrous scaffolds produced by a portable electrohydrodynamic gun for point-of-need wound dressing. International Wound Journal, 2018. 15(5): p. 789-797. 
spraying

\section{Combination of Gyration and Electro-spinning/spraying}

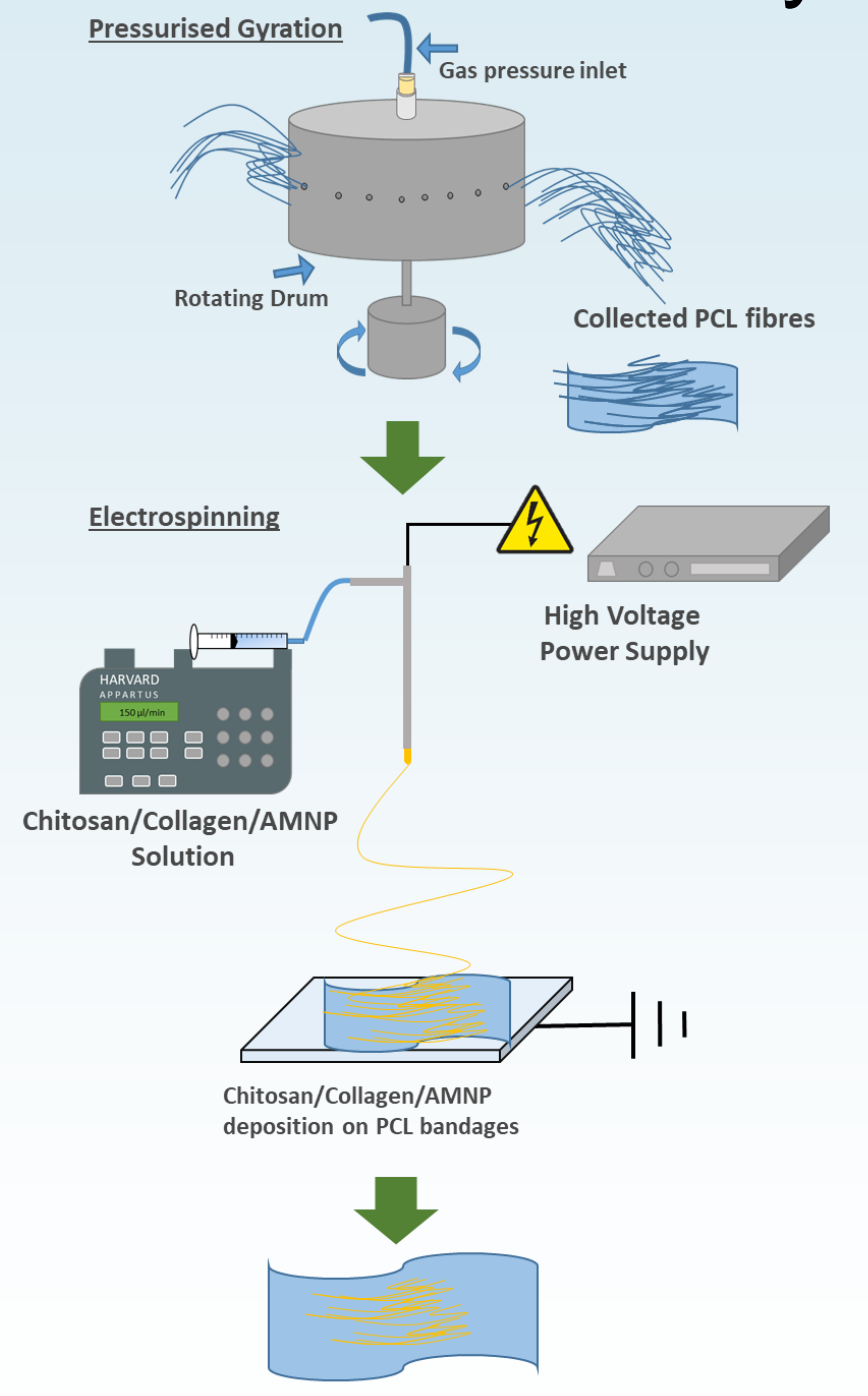

- PCL high-yield fibres produced by gyration which can be collected as bandage-like sheets

- Fibrous ring is cut into pieces and robot transfers bandage to the electrospinning site

- Electrospinning of active nano-fibrous patches made of materials such as collagen and chitosan can be accurately printed onto the bandage

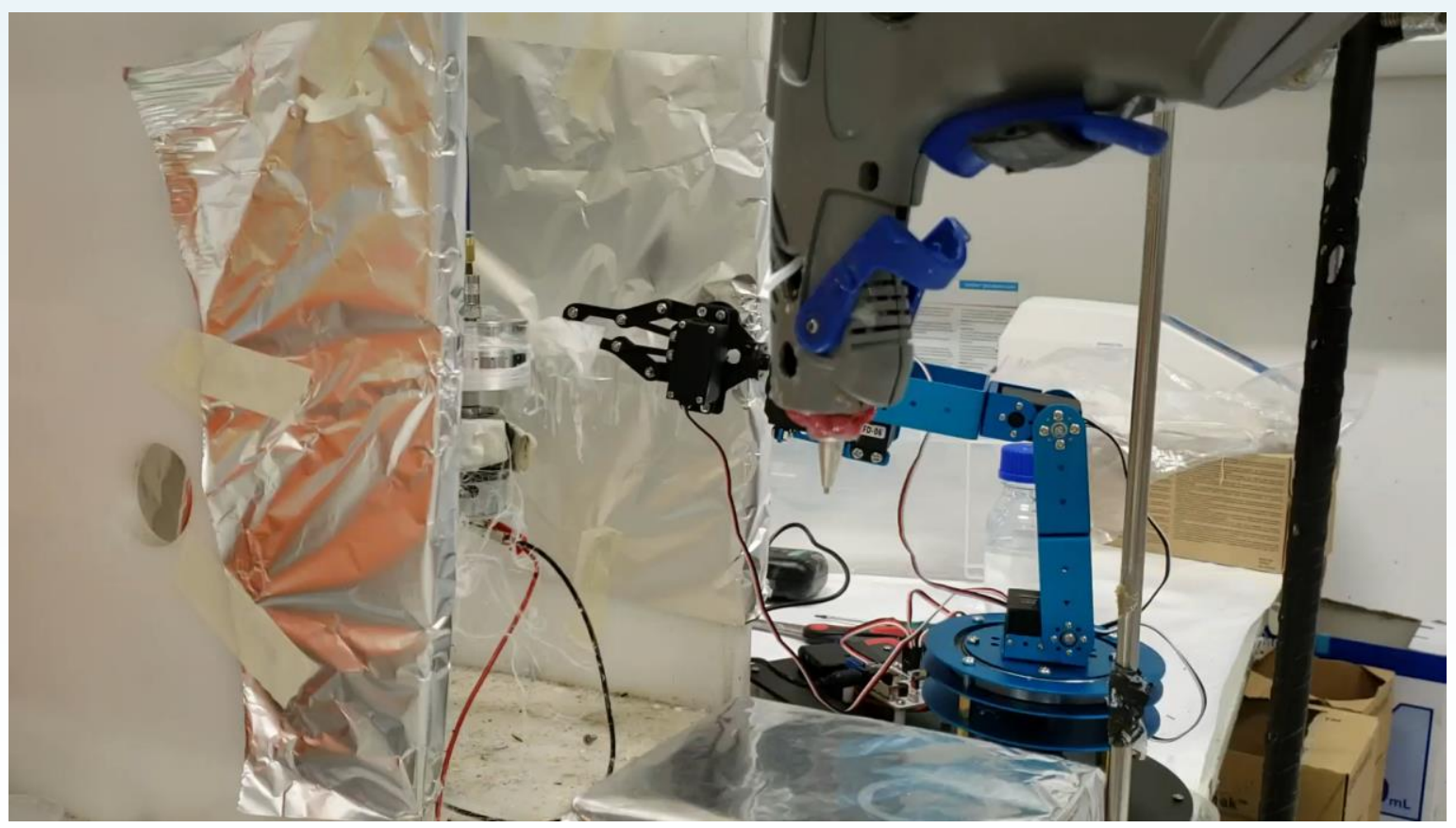


MARMARA UNIVERSITY (MUHAMMAT CAM ET AL.), \& UCL MECHANICAL ENGINEERING

\section{Production of Bioactive Bandages \& Patches}

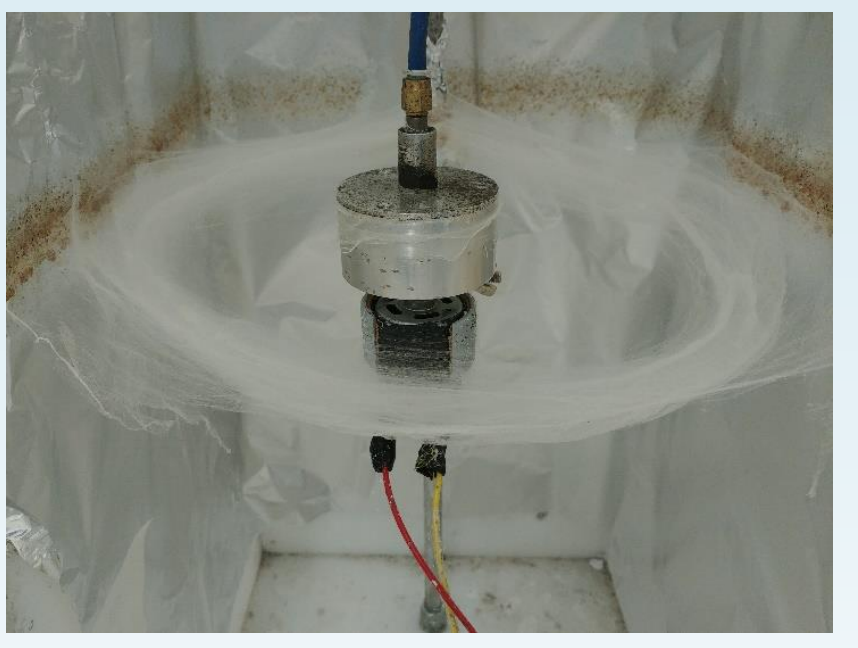

- PCL fibres produced via pressurised gyration which act as the bandage

- Collagen and Chitosan solutions are electrospun onto the bandages to provide a bioactive patch which both protects the wound site from bacterial infections and accelerates the wound healing process.

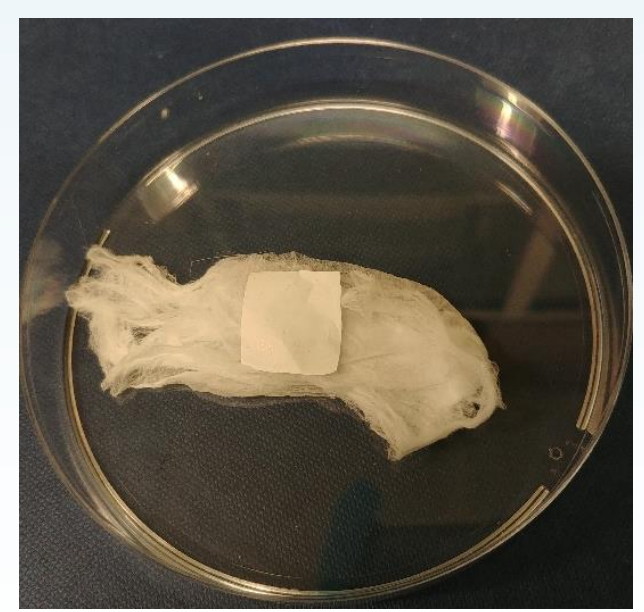

Bandage with patch on $90 \mathrm{~mm}$ Petri dish

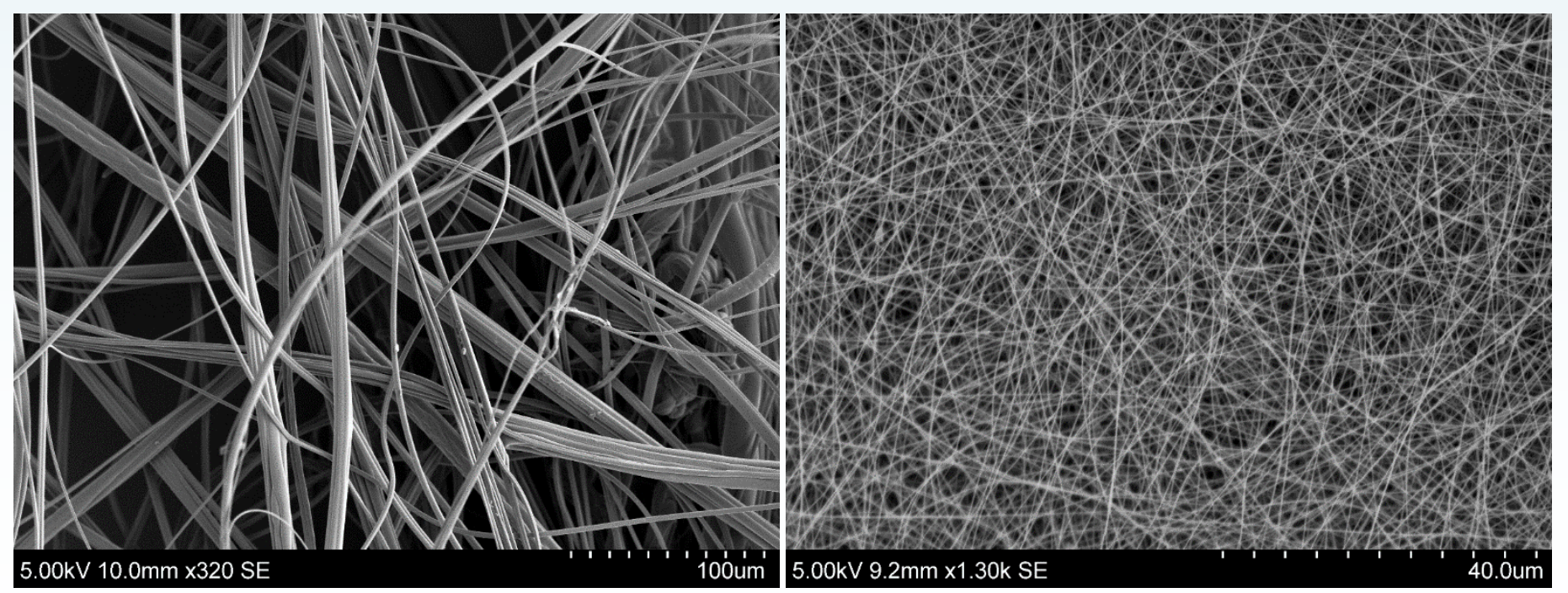

Gyration (1.71 $\pm 0.47 \mu \mathrm{m})$

Electrospinning $(142 \pm 31 \mathrm{~nm})$ 


\section{Next generation wound dressing made of nanofibers incorporated with antimicrobial}

\section{peptides (AMPs).}

- Materials including hydrogels, decellularized dermal porcine dermal matrix and freezing dried or gas foaming scaffolds have been studied for wound healing applications, however, lack the ability to recapitulate the architecture of the skin's extracellular matrix (ECM)

- A new generation of wound dressing materials is anticipated to have a higher moisture level, and thereby provide sustained release results, which will enhance the healing of wounds due to the distinctive biological and non-sterile wound environment and to the difficult process of wound healing ${ }^{1-3}$.

- Pressurised gyration is selected in this research because of its ability to mass produce bandage like meshes with simple separation and enhanced process control 4 .

- A wound dressing material is created by loading peptides into water-soluble polymers that are proficient of efficient release. Thus, the growth of microorganisms is regulated by the antibacterial agents embedded in the structure of the fiber ${ }^{5}$.

- A series of PEO integrated AMP nanofibers are prepared using GH12-COOH-M2 and AMP2 antimicrobial peptides, which are synthesized by solid phase peptide synthesis (SPPS) using an AAPPTec Focus XC peptide synthesizer, supplied by Kansas University (USA).

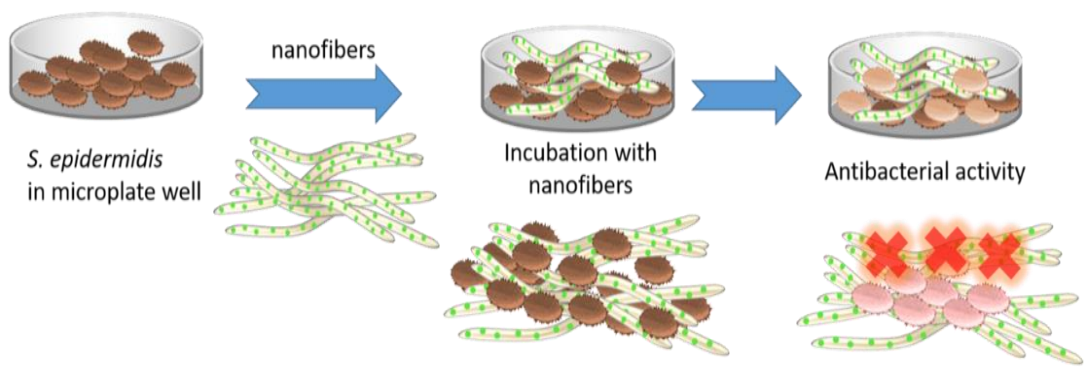

Schematic illustration of the antibacterial assessment of AMP integrated PEO nanofibers

Georgescu, M.; Chifiriuc, M. C.; Marutescu, L.; Gheorghe, I.; Lazar, V.; Bolocan, A.; Bertesteanu, S., Bioactive Wound Dressings for the Management of Chronic Wounds. 2017. Sood, A.; Granick, M. S.; Tomaselli, N. L., Wound Dressings and Comparative Effectiveness Data. 2014.

Gizaw, M.; Thompson, J.; Faglie, A.; Lee, S.-Y.; Neuenschwander, P.; Chou, S.-F., Electrospun Fibers as a Dressing Material for Drug and Biological Agent Delivery in Wound Healing Applications. 2018. Alenezi, H.; Cam, M. E.; Edirisinghe, M., Experimental and theoretical investigation of the fluid behavior during polymeric fiber formation with and without pressure. 2019. Morais, D. S.; Guedes, R. M.; Lopes, M. A., Antimicrobial approaches for textiles: From research to market. 2016 


\section{$\pm=\mid C_{1}$}

\section{Preliminary testing}

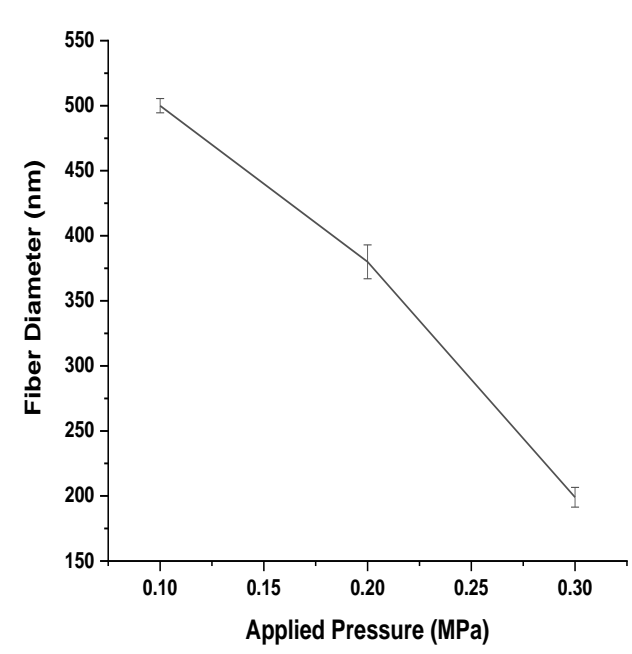

Average fiber diameters using $\mathrm{M} 2$ peptides at $35 \mu \mathrm{g} / \mathrm{mL}$ at $0.1-0.3$ $\mathrm{MPa}$

$\circ$ Average fiber diameter at $0.1 \mathrm{MPa}-$ $0.3 \mathrm{MPa}: 506 \mathrm{~nm} \pm 155,395 \mathrm{~nm} \pm 101$ $\mathrm{nm}$ and $191 \mathrm{~nm} \pm 55 \mathrm{~nm}$ respectively.
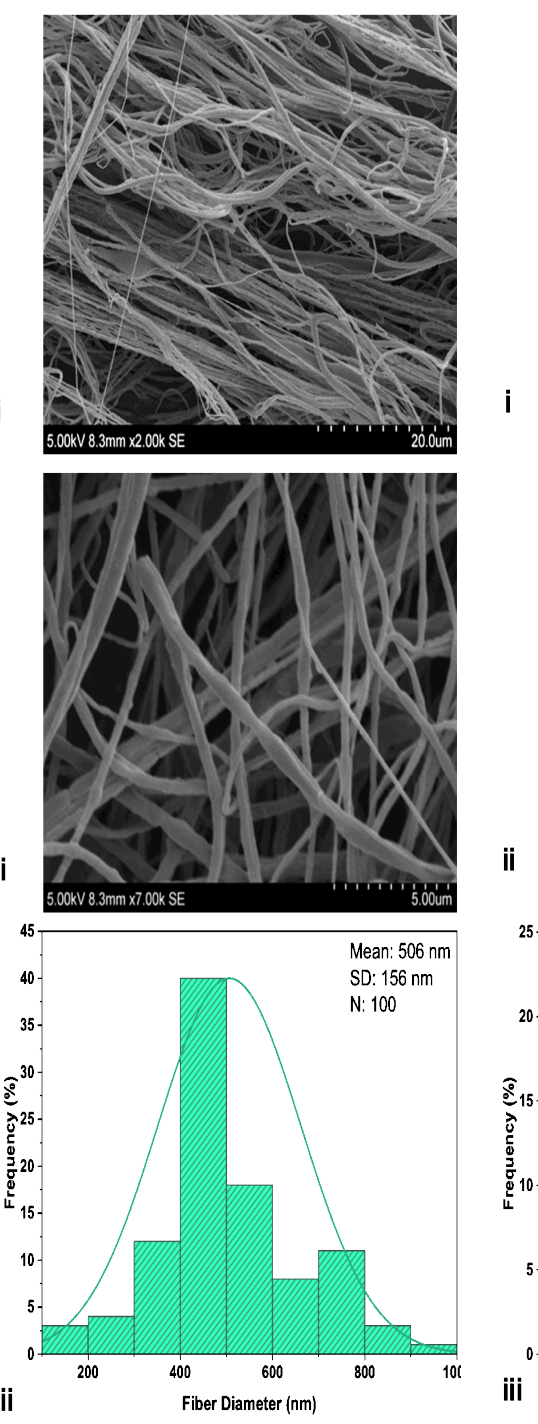
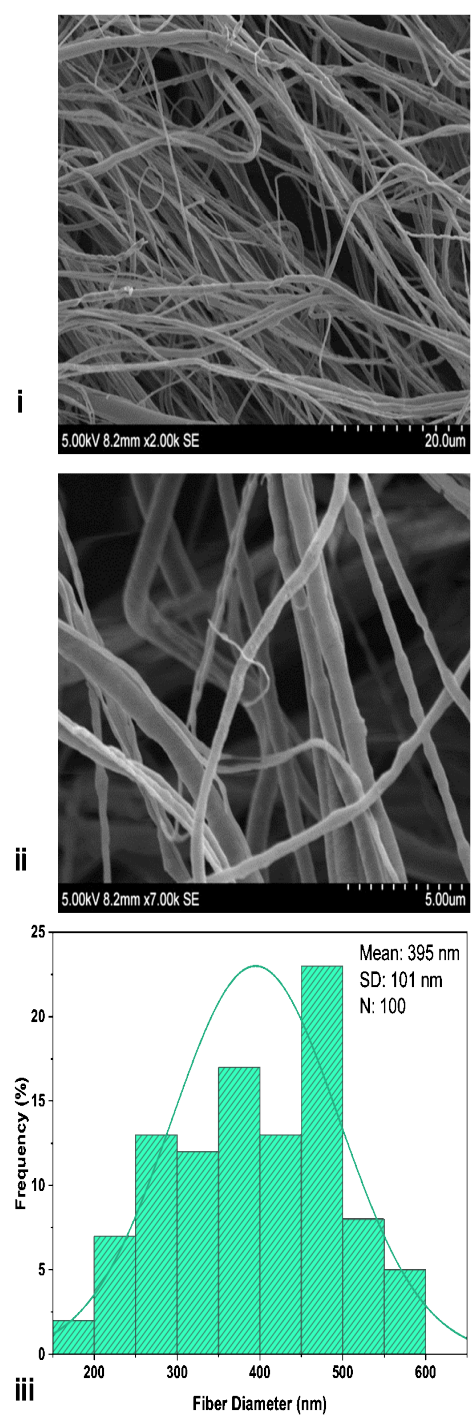

$c$

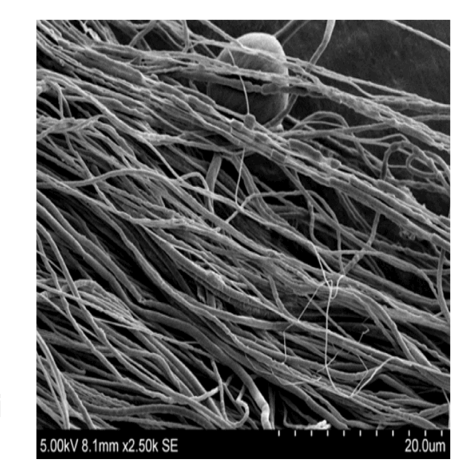

ii
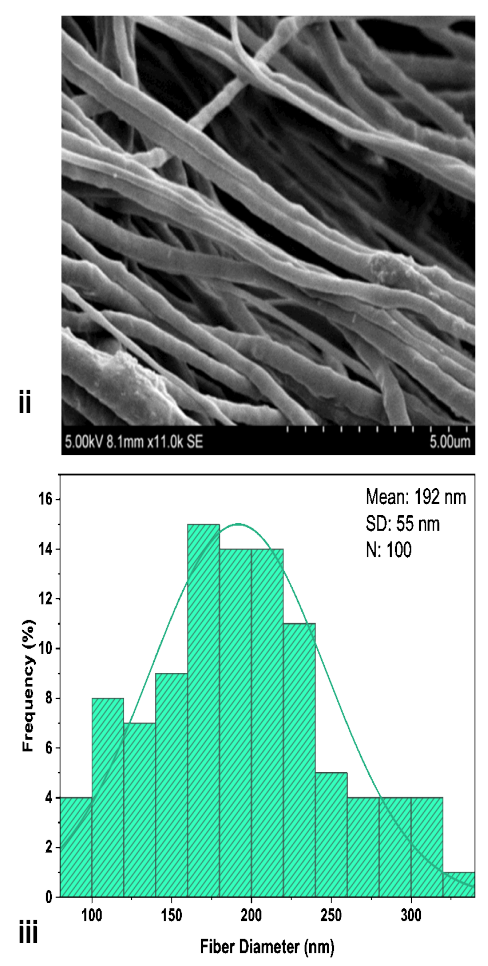

Scanning electron microscopy (SEM) images and size distribution graphs at $15 \%$ PEO/ water using $\mathrm{M} 235 \mu \mathrm{g} / \mathrm{mL}$, a) $0.1 \mathrm{MPa}$, b) $0.2 \mathrm{MPa}$, c) $0.3 \mathrm{MPa}$ 


\section{AMP characterisation using fluorescence microscopy}
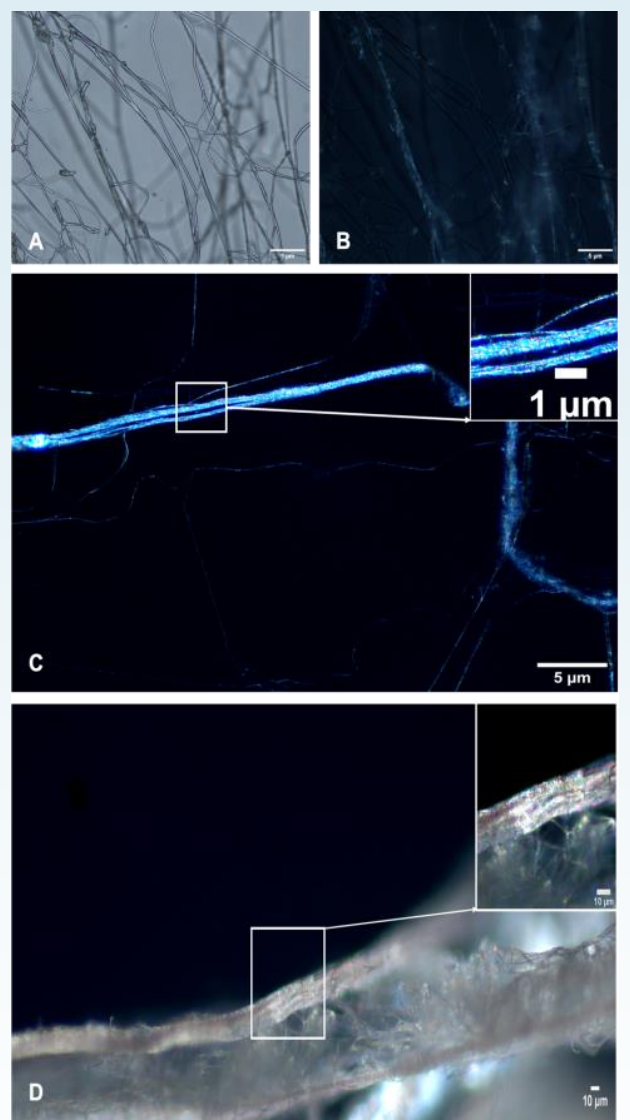

Polarisation contrast images captured on a Zeiss

Axioplan2 microscope, with a $20 x N A 0.5$ objective, a) PEO control without polarisation contrast, b) with polarisation contrast, c) PEO incorporated M2 Peptide, and d) PEO incorporated AMP2 polarization image
- Fluorescence microscopy was used to produce brightfield and polarisation contrast images

- Brightfield image $A$, and polarisation image B both serve as PEO control fibers. Images display fibers without attachment, this confirms samples are pure PEO fibers only

O Both polarisation images C and D display attachment of peptides (M2 and AMPs at $105 \mu \mathrm{g} / \mathrm{mL}$ ) dispersed evenly inside and along fiber surface, illustrated as dots

- AMPs are embedded in the polymer matrix and fiber surface.

\section{Bacterial viability}

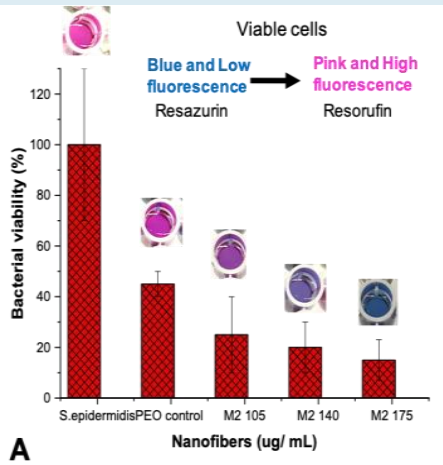

Antimicrobial effect of PEO fibers loaded with M2 peptides $(105 \mu \mathrm{g} / \mathrm{mL}-175$ $\mu \mathrm{g} / \mathrm{mL}$ ) against S. epidermidis evaluated with AlamarBlue cell viability assay

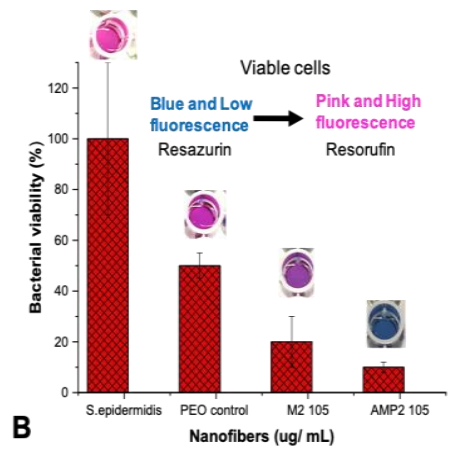

Comparison of antimicrobial effect of PEO fibers loaded with M2 and AMP2 at $105 \mu \mathrm{g} / \mathrm{mL}$ against S. epidermidis
- Bacterial viability was assessed at various concentrations using only $\mathrm{M} 2$ integrated PEO nanofibers

O An increase in the $M 2$ content has produced greater antimicrobial activity.

Comparison of bacterial viability at $105 \mathrm{ug} / \mathrm{mL}$ using $\mathrm{M} 2$ and $\mathrm{AMP} 2$ suggest that antimicrobial activity was significantly higher using AMP2, indicating a greater release rate when tested against $S$. epidermidis. 


\section{Fourier-transform infrared spectroscopy}

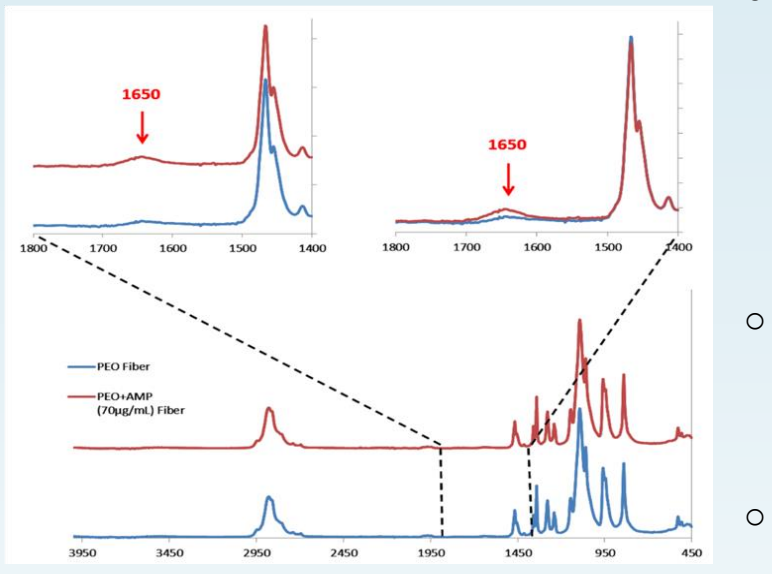

FTIR spectra of the nanofiber samples
FTIR depicts that characteristic peaks of PEO observed at $2900 \mathrm{~cm}^{-1}$ (methylene group $\mathrm{CH} 2$ molecular stretching), and at $1100 \mathrm{~cm}^{-1}$ and $960 \mathrm{~cm}^{-1}$ (C O C group stretching)

FTIR results showed that there was no change in chemical structure as a result of M2 integration to fibers

FTIR of $M 2$ samples integrated with PEO in two different concentrations did not reveal new chemical bonds

- Therefore, FTIR peaks of PEO fiber and fiber samples containing $\mathrm{M} 2$ are similar.

\section{Antimicrobial peptide structures}

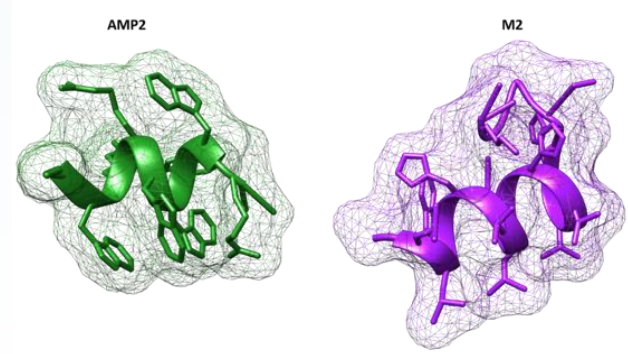

Secondary structure models for AMP2 and M2 peptides
- Secondary structure models of the peptides were obtained from the amino acid sequences using PEP-FOLD 3.5.8

○ Chimeric peptides with AMP2 incorporated demonstrated effective antibacterial function against $S$. epidermidis bacteria.

\section{Conclusions}

- The novel PEO nanofibers incorporated with $M 2$ and AMP2 peptides generated an effective antibacterial activity against $S$. epidermidis to enhance wound healing applications

- The nanofibers created a high efficiacy against $S$. epidermidis which is a common bacteria accociated with wounds

- AlamarBlue assay confirms that AMP2 (105 $\mathrm{\mu g} / \mathrm{mL}$ ) performed the greatest antibacterial activity

- Therefore, loading antibacterial peptides with water soluble polymers such as PEO is an effective delivery method for the easy release of antimocrobial agents into a wound site

- Using water-based systems also allows to be more environmentally friendly whilst also ensurng maximum biocompatability in an open wound scenario. 


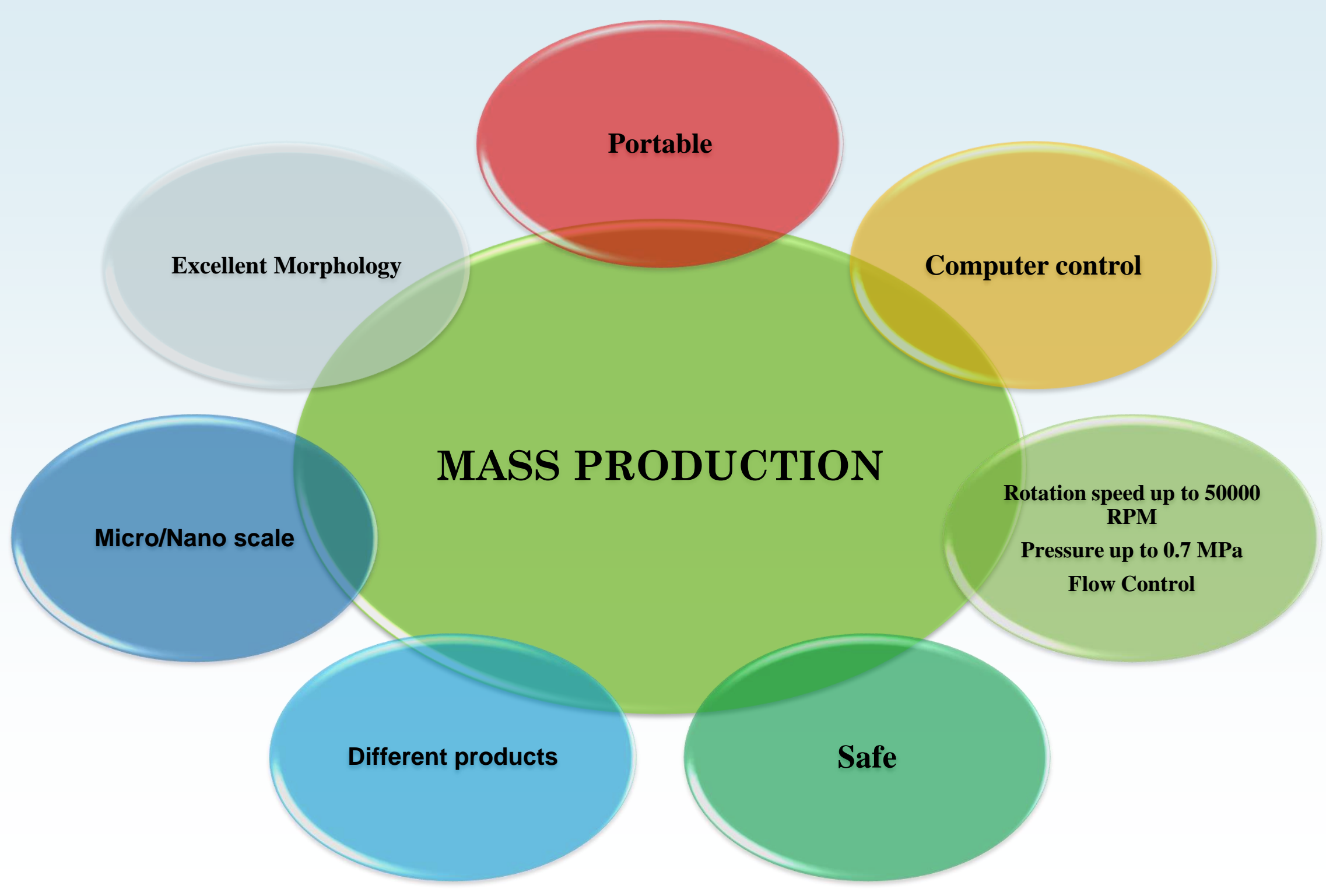




\section{UCL MECHANICAL ENGINEERING \& GOVT. OF KUWAIT A M C,}
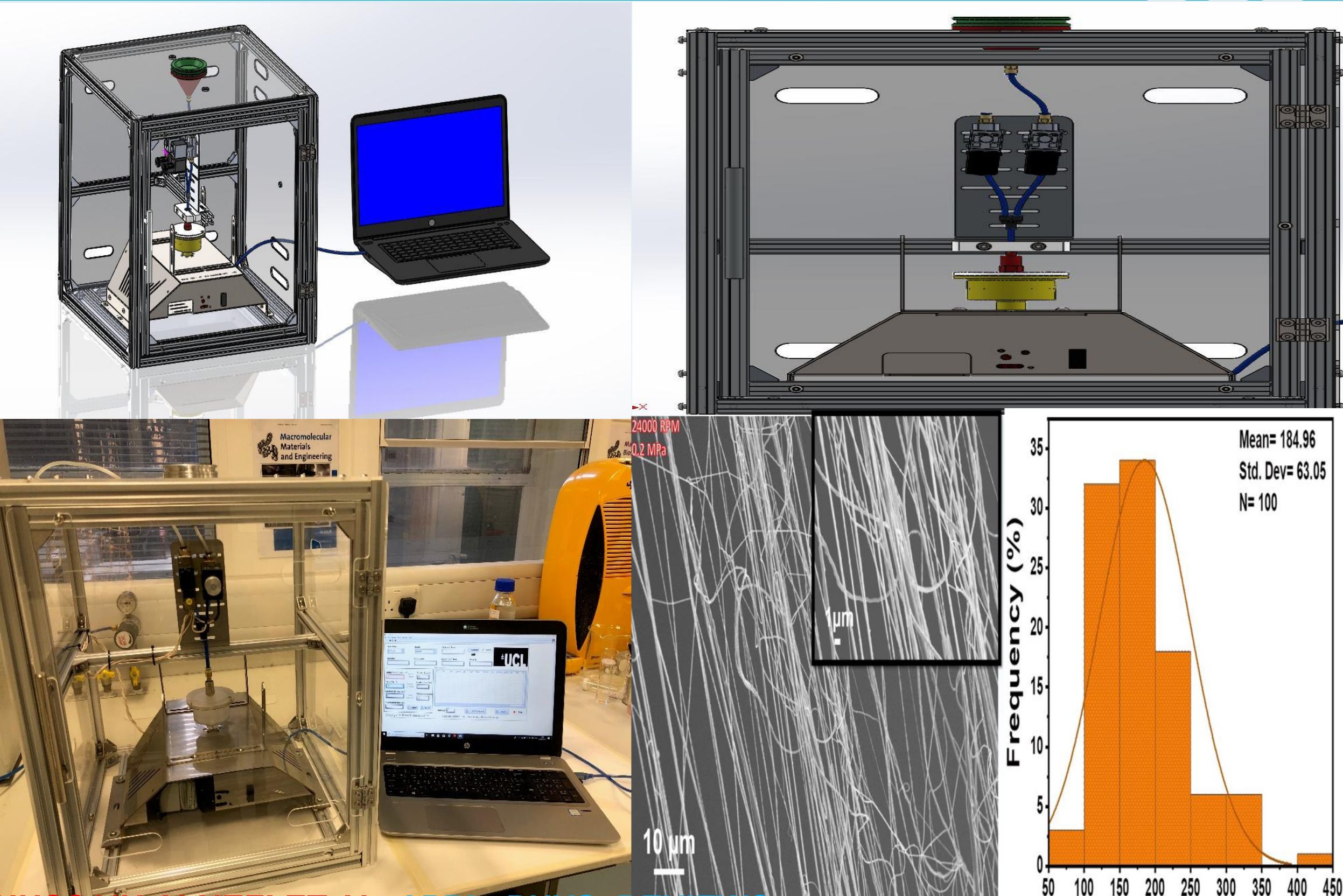

10) $\mathrm{m}$
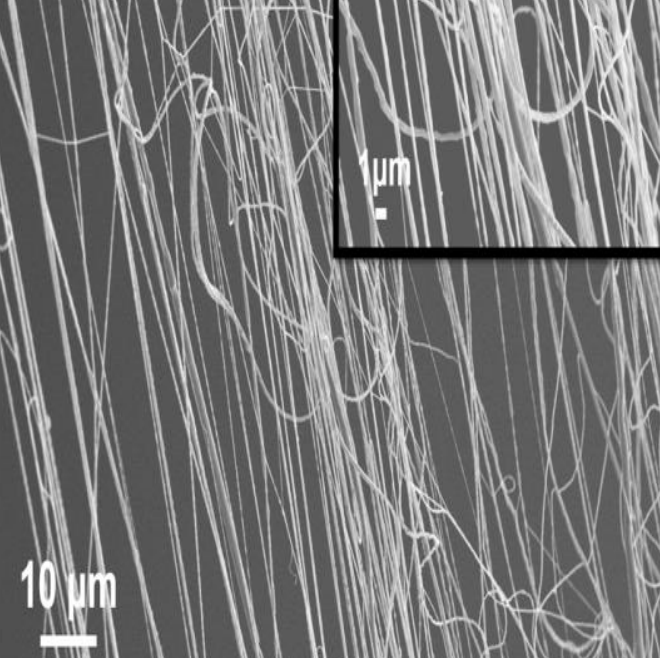

HUSSAFAENEZI ET AL IPPL. PH inI

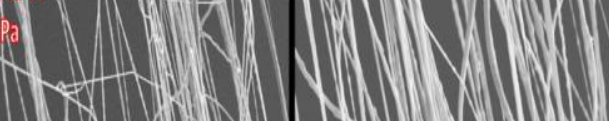

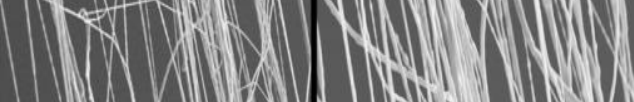

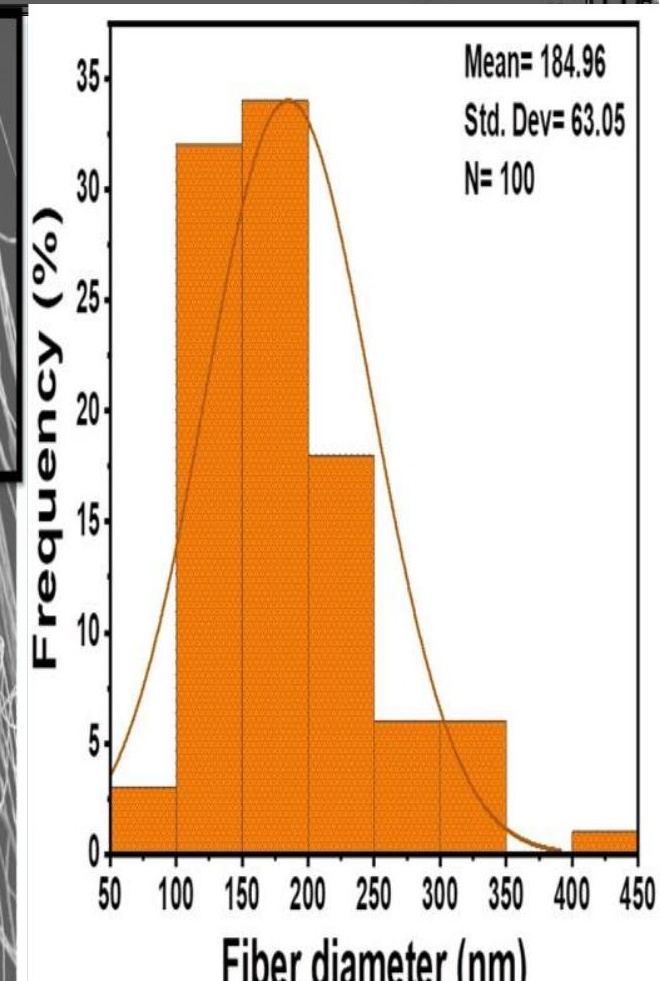




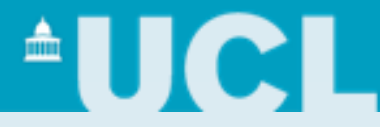

Experimental and theoretical investigation of the fluid behavior during

polymeric fiber formation with and without pressure

\section{C.S at 7000.8500 and 10000 rpm no pressure VS}
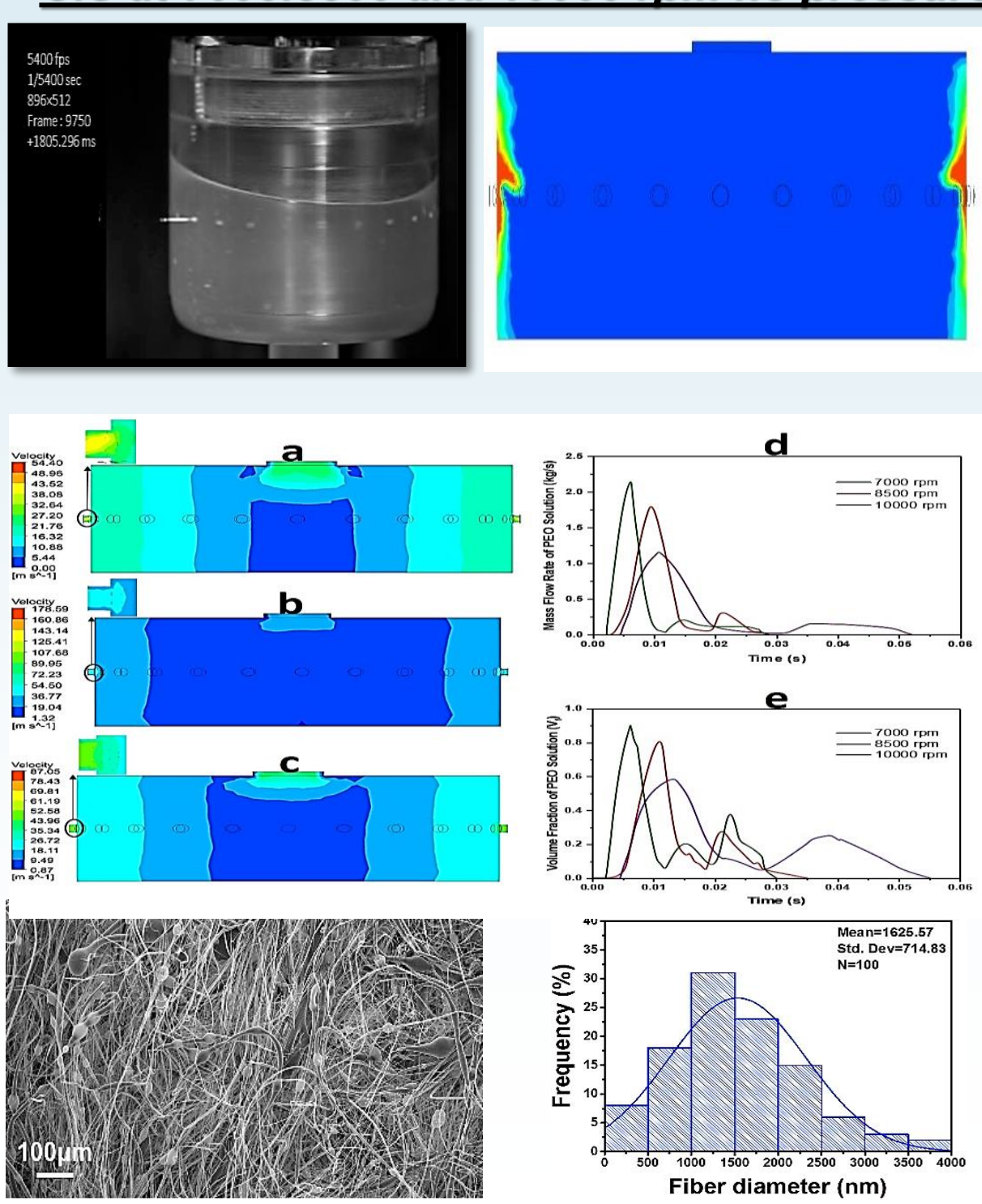

P.G at $10000 \mathrm{rpm}$ at $0.1,0.2$ and $0.3 \mathrm{MPa}$
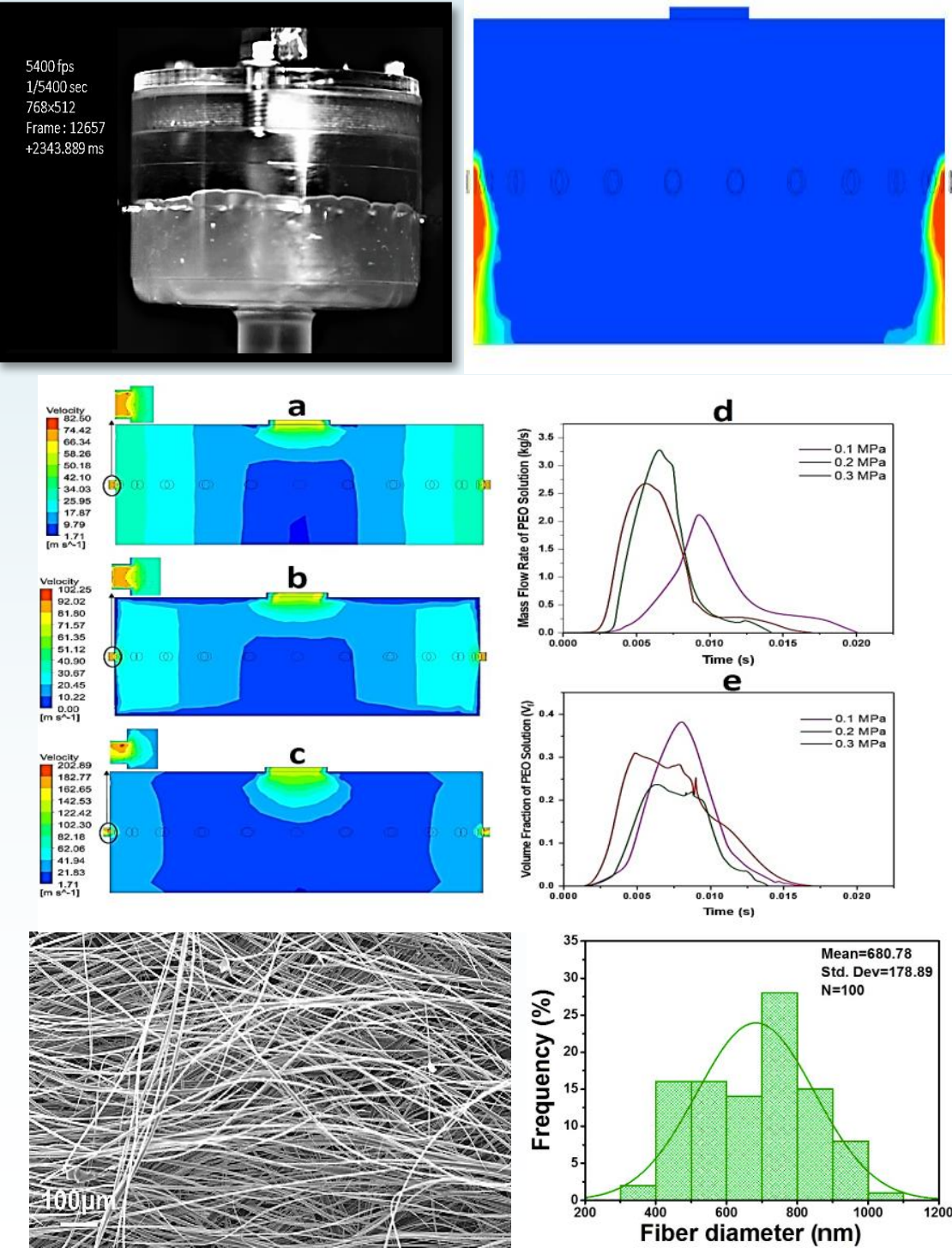


\title{
Groundbreaking Research on Polymeric Fibers
}

\section{Creating Miracles with Polymeric Fibers}

\author{
Amer Inst Phys News 15 ${ }^{\text {th }}$ October 2019
}

https://publishing.aip.org/publications/latestcontent/creating-miracles-with-polymeric-fibers/

https://publishing.aip.org/publications/latest-content/creating-miracles-with-polymeric-fibers/

https://products.aip.org/apr/media/?utm source=Scitation\&utm medium=Display\&utm campaign=Firstarticles\&utm term=August\&utm content=firstarticles

https://phys.org/news/2019-10-fabrication-polymeric-fibers-advanced-health.html

https://www.sciencedaily.com/releases/2019/10/191015131616.htm

https://www.parallelstate.com/news/researchers-studied-the-fabrication-of-polymeric-fibers-for-use-in-advanced-health-care/175626

https://www.eurekalert.org/multimedia/pub/213920.php

Experimental and theoretical investigation of the fluid behavior during polymeric fiber formation with and without pressure Applied Physics Reviews 6, 041401 (2019); https://doi.org/10.1063/1.5110965

Hussain Alenezi $^{1,2}$, Muhammet Emin Cam ${ }^{1,3,4}$, and Mohan Edirisinghe $^{1, a)}$ 


\section{Key Sponsors}

- The Royal Society, The Wolfson Foundation

- Leverhulme Trust

- Unilever

- Worshipful Co. Armourers \& Brasiers

- Islamic Development Bank

- Orthopaedic Research UK (Furlong Foundation)

- JRI Orthopaedics Ltd

\section{- Danish Research Council, Veloxis Pharmaceuticals}

Key Academic/Other Collaborations

- University of Oxford -UCL Div. of Medicine, UCLH, Moorfields

-UCL School of Pharmacy, UCL Business

- University of Cambridge

- University of Hertfordshire

- University of Sheffield

--Marmara University

- University of Padua

- Hacettepe University

- China University of Geosciences, Beijing, China

--University of Kansas

--University of Sichuan, Chengdu, China

--North Dakota University

--Helsinki University

--National Institute for Materials Science, Ibaraki, Japan

\section{EPSRC}

Engineering and Physical Sciences

Research Council

Research Group in the Biomaterials Processing \&

Forming Laboratory Website:

\section{www.EdirisingheLab.com}

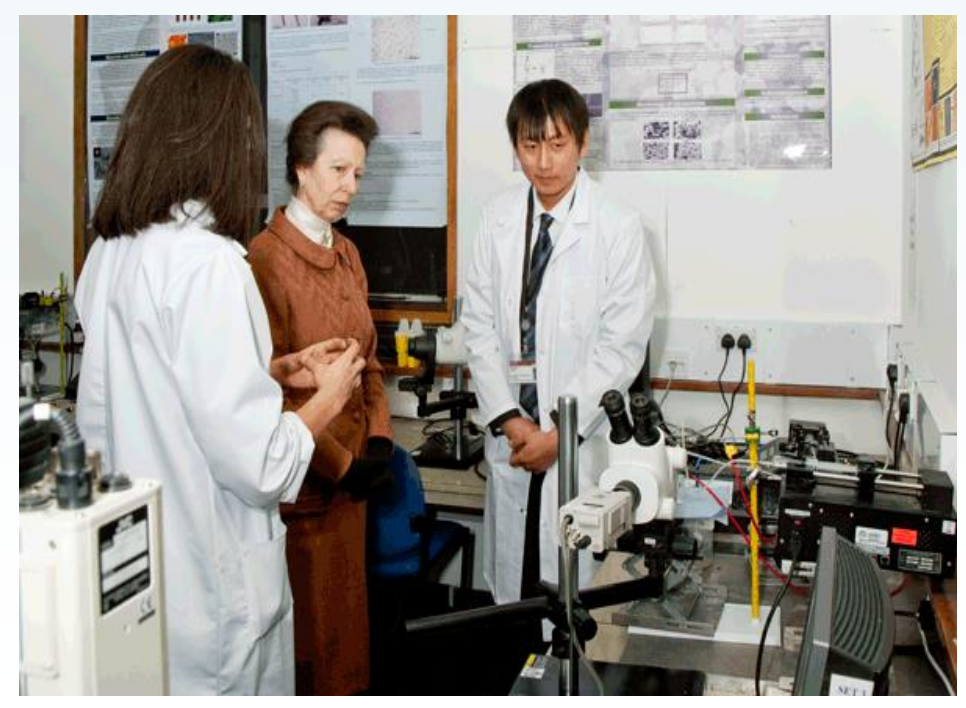

